Research Article

\title{
Ex Vivo Expansion of Murine MSC Impairs Transcription Factor-Induced Differentiation into Pancreatic $\beta$-Cells
}

\author{
Dario Gerace $(\mathrm{D}),{ }^{1}$ Rosetta Martiniello-Wilks ${ }^{\mathrm{D}},{ }^{1,2}$ Rosaline Habib, ${ }^{1}$ Binhai Ren $(\mathrm{D}),{ }^{1}$ \\ Najah Therese Nassif ${ }^{D},{ }^{1}$ Bronwyn Anne O’Brien (D), ${ }^{1}$ and Ann Margaret Simpson (iD) \\ ${ }^{1}$ The School of Life Sciences and Centre for Health Technologies, Faculty of Science, University of Technology Sydney, \\ Sydney, Australia \\ ${ }^{2}$ Translational Cancer Research Group, University of Technology Sydney, Sydney, Australia
}

Correspondence should be addressed to Ann Margaret Simpson; ann.simpson@uts.edu.au

Received 17 July 2018; Revised 14 November 2018; Accepted 15 November 2018; Published 10 March 2019

Guest Editor: Emilio Satoshi Hara

Copyright ( 2019 Dario Gerace et al. This is an open access article distributed under the Creative Commons Attribution License, which permits unrestricted use, distribution, and reproduction in any medium, provided the original work is properly cited.

Combinatorial gene and cell therapy as a means of generating surrogate $\beta$-cells has been investigated for the treatment of type 1 diabetes (T1D) for a number of years with varying success. One of the limitations of current cell therapies for T1D is the inability to generate sufficient quantities of functional transplantable insulin-producing cells. Due to their impressive immunomodulatory properties, in addition to their ease of expansion and genetic modification ex vivo, mesenchymal stem cells (MSCs) are an attractive alternative source of adult stem cells for regenerative medicine. To overcome the aforementioned limitation of current therapies, we assessed the utility of ex vivo expanded bone marrow-derived murine MSCs for their persistence in immune-competent and immune-deficient animal models and their ability to differentiate into surrogate $\beta$-cells. $\mathrm{CD} 45^{-} / \mathrm{Ly}^{+}$murine MSCs were isolated from the bone marrow of nonobese diabetic (NOD) mice and nucleofected to express the bioluminescent protein, Firefly luciferase (Luc2). The persistence of a subcutaneous (s.c.) transplant of Luc2-expressing MSCs was assessed in immune-competent (NOD) $(n=4)$ and immune-deficient (NOD/Scid $)(n=4)$ animal models of diabetes. Luc2-expressing MSCs persisted for 2 and 12 weeks, respectively, in NOD and NOD/Scid mice. Ex vivo expanded MSCs were transduced with the HMD lentiviral vector $(\mathrm{MOI}=10)$ to express furin-cleavable human insulin $(I N S-F U R)$ and murine NeuroD1 and $P d x 1$. This was followed by the characterization of pancreatic transdifferentiation via reverse transcriptase polymerase chain reaction (RT-PCR) and static and glucose-stimulated insulin secretion (GSIS). INS-FUR-expressing MSCs were assessed for their ability to reverse diabetes after transplantation into streptozotocin- (STZ-) diabetic NOD/Scid mice $(n=5)$. Transduced MSCs did not undergo pancreatic transdifferentiation, as determined by RT-PCR analyses, lacked glucose responsiveness, and upon transplantation did not reverse diabetes. The data suggest that ex vivo expanded MSCs lose their multipotent differentiation potential and may be more useful as gene therapy targets prior to expansion.

\section{Introduction}

T1D results from the autoimmune destruction of the pancreatic insulin-producing $\beta$-cells, which leads to hyperglycaemia and the lifelong dependence on exogenous insulin therapy [1]. Currently, the only cures for T1D are pancreas or islet transplantation; however, these interventions are limited by a shortage of donor organs and the requirement for lifelong immunosuppression [2]. To overcome the limitations of current therapies, a promising alternative strategy is the ex vivo generation of surrogate $\beta$-cells through the directed-differentiation of nonpancreatic target cells [3-10].

Pancreatic transcription factors play an important role both in islet cell differentiation and specialization and mature $\beta$-cell function during embryonic and neonatal development and adult life, respectively $[11,12]$. Our laboratory and others have investigated the direct transfer of $\beta$-cell transcription factors and insulin as mediators of pancreatic transdifferentiation in nonpancreatic cells/tissues with varying success $[3-5,13-17]$. We have previously shown that the endocrine-specifying transcription factor, NeuroD1, 
which lies downstream of $P d x 1$ in the transcription factor hierarchy of pancreatic development, was capable of inducing pancreatic transdifferentiation of a rat hepatocyte cell line (H4IIE). Transdifferentiation was characterized by the upregulation of both upper and lower hierarchy pancreatic transcription factors, without the development of exocrine differentiation $[12,18]$. In addition, due to the overexpression of the furin-cleavable human insulin (INS-FUR) gene (a modified form of human proinsulin, which permits cleavage into mature insulin via furin enzymes in nonpancreatic cells), these cells were capable of synthesizing, storing, and secreting mature human insulin in a glucose-responsive manner and reversed diabetes upon transplantation in STZ-diabetic NOD/Scid mice [18]. However, one of the current challenges of clinical translation of combinatorial gene and cell therapies for T1D is upscaling the production of functional surrogate $\beta$-cells [19].

Due to their high plasticity, immunomodulatory properties, fewer ethical concerns, and ease of ex vivo expansion and gene modification [20, 21], MSCs are an attractive alternative target cell for the autologous and allogeneic treatment of T1D. Several studies have investigated the ex vivo targeting of MSCs for transdifferentiation into islet progenitor cells (IPCs) via viral-mediated transfer of pancreatic transcription factors [14-17]. Previously, the transfer of the "master regulator" of pancreatic differentiation, $P d x 1$, to MSCs resulted in their differentiation into glucose-responsive IPCs, which reversed diabetes, for a period of 6-8 weeks (experimental endpoint), upon transplantation into STZ-diabetic NOD/Scid mice [14]. However, $P d x 1$ transfer has also been associated with exocrine differentiation and concomitant tissue damage, which is undesirable for a T1D cell replacement therapy [22]. Therefore, in this study, we assessed the pancreatic differentiation potential of ex vivo expanded murine bone marrow-derived MSCs as a preclinical model to overcome the shortage limitations of current therapies, via the overexpression of murine NeuroD1 and INS-FUR using a lentiviral vector. We found that due to a loss of the intrinsic multipotent differentiation potential of MSCs with increasing culture, transcription factor-mediated $\beta$-cell differentiation, via the forced expression of NeuroD1 and INS-FUR, failed to occur. This was confirmed via the overexpression of murine $P d x 1$, which is known to induce $\beta$-cell differentiation of MSCs at early passage numbers. The data highlight the limited timeframe for MSCs to function as effective gene therapy targets and suggest that MSCs do not represent a suitable alternative source of cells to overcome the shortage limitations of current $\beta$-cell replacement therapies.

\section{Methods}

2.1. Sourcing of Animals. NOD and NOD/Scid mice were sourced from the Animal Resources Centre (WA, Australia). All animal work was approved by the UTS Animal Care and Ethics Committee (ACEC 2011-447A; ACEC 2009-244A) and complied with the Australian code for the care and use of animals for scientific purposes [23].
2.2. MSC Isolation and Cell Culture. Bone marrow was flushed from the femurs of female NOD mice (6-8weeks old), and the cell pellet was resuspended in standard MSC medium ( $\alpha$-minimal essential media (MEM), 1\% v/v 100x Penicillin/Streptomycin/L-Glutamine (P/S/G) with $20 \% \mathrm{v} / \mathrm{v}$ Fetal Bovine Serum (FBS)) (Gibco ${ }^{\infty}$, Thermo Fisher) and incubated at $37^{\circ} \mathrm{C} / 5 \% \mathrm{CO}_{2}$. Plastic-adherent stromal cells were subcultured for two passages (with epiphyses) prior to fluorescence-activated cell sorting (FACS).

Passage 2 plastic-adherent stromal cells $\left(5 \times 10^{5}\right.$ cells $)$ were resuspended in sorting buffer (1x Hanks Balanced Salt Solution (HBSS) supplemented with 5\% v/v FBS) and stained with $0.2 \mathrm{mg} / \mathrm{ml}$ rat anti-mouse CD45 monoclonal antibody $(\mathrm{mAb})$ conjugated to allophycocyanin (APC) (BD Pharmingen $^{\mathrm{TM}}$, USA) and $0.2 \mathrm{mg} / \mathrm{ml}$ rat anti-mouse Ly6 (Sca-1) $\mathrm{mAb}$ conjugated to phycoerythrin (PE) (BD Pharmingen ${ }^{\mathrm{TM}}$, USA). Stained stromal cells were sorted by FACS at the Advanced Cytometry Facility (Centenary Institute, Sydney, Australia) using a BD FACSAria ${ }^{\mathrm{TM}}$ II flow cytometer and analysed using BD FACSDiva ${ }^{\mathrm{TM}}$ software (Version 6.1.3). The stromal cells were sorted into $\mathrm{CD} 45^{-} / \mathrm{Ly}^{+}$(MSCs) and $\mathrm{CD} 45^{+} / \mathrm{Ly}^{+}$ (double positive) cell populations. Sorted cells were resuspended in complete medium and incubated at $37^{\circ} \mathrm{C} / 5 \%$ $\mathrm{CO}_{2}$. Following cell attachment, $10 \mathrm{ng} / \mathrm{ml}$ basic fibroblast growth factor (bFGF) was added to the standard MSC medium, in which the parental stromal cells and sorted cells were cultured thereafter.

2.3. MSC Proliferation and Clonogenicity. For proliferation assays, MSCs at early (P3-15), mid (P15-30), and late (P30-60) passage numbers were seeded in 24-well plates $\left(2.5 \times 10^{3}\right.$ cells/well) (Falcon ${ }^{\circledast}$ BD Biosciences, San Jose, USA) in triplicate and maintained in standard MSC medium for 15 days, with the medium replenished weekly. Cell viability was assessed by Trypan blue $\left(0.4 \% \mathrm{v} / \mathrm{v} ;\right.$ Gibco ${ }^{\oplus}$, Thermo Fisher) exclusion. Total cell and viable cell numbers were determined and represented as mean \pm standard deviation (SD) for each time point $(n=3)$.

For clonogenicity assays, MSCs at early, mid, and late passage numbers were seeded in $10 \mathrm{~cm}^{2}$ tissue culture-treated plates $\left(5 \times 10^{2}\right.$ cells/plate) (Falcon ${ }^{\circledR}$ BD Biosciences) and maintained in standard MSC medium for 10 days. Colonies were stained with $0.4 \% \mathrm{v} / \mathrm{v}$ methylene blue in methanol and counted by microscopy. Data were represented as mean colony count per 5000 cells \pm SD $(n=3)$. Standard MSC medium was replenished weekly.

2.4. Morphological Analysis. Images of four fields of view at 10x or 20x magnification were acquired at early, mid, and late passage numbers using a Leica ${ }^{\Theta}$ DM microscope (Leica Microsystems ${ }^{\odot}$, Wetzlar, Germany) and processed using the image processing software, Leica Application Suite (V4.4.0) (Leica Microsystems ${ }^{\odot}$ ). Scale bars on figures are equivalent to $100 \mu \mathrm{m}$.

2.5. Gene Expression Profiling. Total RNA was extracted using TRIzol ${ }^{\infty}$ Reagent (Thermo Fisher ${ }^{\oplus}$, Waltman, USA) and samples were treated with DNase I, Amplification Grade (Thermo Fisher ${ }^{\circledast}$ USA), before cDNA synthesis using 
SuperScript III First-Strand Synthesis SuperMix (Thermo Fisher ${ }^{\infty}$ USA). RT-PCR was subsequently performed using an Eppendorf Mastercycler (Eppendorf ${ }^{\mathrm{TM}}$, Hamburg, Germany) to determine the relative expression levels of selected pancreatic genes using GoTaq PCR Master Mix (Promega ${ }^{\circledast}$, Madison, USA) and the previously published oligonucleotide sequences and optimised PCR protocols (Supplementary Table 1) [4]. PCR products were imaged after electrophoresis on a $1 \% \mathrm{w} / \mathrm{v}$ agarose gel stained with 10000x GelRed ${ }^{\mathrm{TM}}$ (Biotium ${ }^{\circledR}$, Fremont, USA) $(1: 100000)$ on the InGenius3 (Syngene, Frederick, USA) UV transilluminator using the GeneSys image acquisition software (Syngene ${ }^{\oplus}$ ).

\subsection{Differentiation Assays}

2.6.1. Adipogenesis. Early, mid, and late passage number cells were seeded in standard MSC medium in 24-well plates $\left(2.5 \times 10^{4}\right.$ cells/well $)$ in triplicate and grown to $80-90 \%$ confluence. The medium was subsequently replenished with either adipogenic control or differentiation medium, as previously described [24]. The cells were stained with $0.2 \% \mathrm{w} / \mathrm{v}$ Oil Red O in methanol (Fronine ${ }^{\circledR}$, Sydney, Australia) and semiquantitatively scored as previously described [24]. Values were expressed as count per $\mathrm{cm}^{2}$ and were represented as means \pm SDs $(n=3)$.

2.6.2. Osteogenesis. Early, mid, and late passage cells were seeded in standard MSC medium in 24-well plates $\left(1.25 \times 10^{4}\right.$ cells/well $)$ in triplicate and grown to $90-95 \%$ confluence. The medium was subsequently replenished with either osteogenic control or differentiation medium, as previously described [24]. The cells were stained with $2 \%$ w/v Alizarin Red S (pH 4.1) (Fronine ${ }^{\circ}$ ) and semiquantitatively scored, as previously described [24]. Values were expressed as count per $\mathrm{cm}^{2}$ and were represented as means \pm SDs $(n=3)$.

2.6.3. Chondrogenesis. Early, mid, and late passage cells were seeded in 24 -well plates $\left(1.25 \times 10^{4}\right.$ cells/well $)$ and grown to $90 \%$ confluence in standard MSC medium. The medium was subsequently replenished with either control (MesenCult $^{\mathrm{TM}}$-ACF Chondrogenic Differentiation Basal Medium (STEMCELL Technologies ${ }^{\circledR}$ Vancouver, Canada) with $2 \mathrm{mM}$ L-glutamine) or differentiation (MesenCult ${ }^{\mathrm{TM}}$-ACF Chondrogenic Differentiation Basal Medium, $2 \mathrm{mM}$ L-glutamine, MesenCult ${ }^{\mathrm{TM}}$-ACF 20X Chondrogenic Differentiation Supplement) medium and incubated at $37^{\circ} \mathrm{C} / 5 \%$ $\mathrm{CO}_{2}$ for 18 days. On day 18 , the cells were fixed in $10 \% \mathrm{v} / \mathrm{v}$ neutral buffered formalin and stained with Alcian blue solution (8x, pH 2.5) (Sigma-Aldrich ${ }^{\mathrm{TM}}$, Sydney, Australia). Chondrogenesis was visualised by Alcian blue staining of filamentous glycosaminoglycans.

2.7. Construction of Mammalian Plasmid pVITRO-Luc2. The manipulation of genetic material and generation of genetically modified organisms were approved by the UTS Biosafety Committee (2001-19-R-GC; 2009-02-R-GC). The luciferase reporter gene Luc2 (Photinus pyralis), encoded

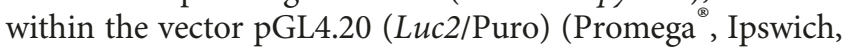

USA), was digested with the restriction enzymes, EcoRV-HF ${ }^{\circledast}$ and BamHI-HF ${ }^{\odot}$ (New England Biolabs ${ }^{\infty}$, San Diego, USA), and ligated into the mammalian dual expression plasmid pVITRO2-hygro -mcs (InvivoGen ${ }^{\circledR}$, San Diego, USA) to generate the mammalian bioluminescence plasmid pVITRO2-Luc2 (Supplementary Figure 1a).

2.8. Nucleofection. Early passage MSCs $\left(1 \times 10^{6}\right.$ cells $)$ were nucleofected with $5 \mu \mathrm{g}$ pVITRO2-Luc2 and $2 \mu \mathrm{g}$ pmax-GFP ${ }^{\oplus}$, according to the manufacturer's instructions (Lonza ${ }^{\mathrm{TM}}$, Basel, Switzerland), using the Nucleofector ${ }^{\mathrm{TM}} 2 \mathrm{~b}$ device $\left(\operatorname{Lonza}^{\mathrm{TM}}\right)$. Following nucleofection, the cells were returned to culture in standard MSC medium at $37^{\circ} \mathrm{C} / 5 \% \mathrm{CO}_{2}$ for one week. Stable clones were then selected using $200 \mu \mathrm{g} / \mathrm{ml}$ Hygromycin B (Thermo Fisher Scientific ${ }^{\oplus}$ ) over a two-week period.

2.9. In Vitro Bioluminescence Imaging (BLI). In vitro BLI of a linear concentration of midpassage MSC-Luc2 and the cell line MSC-Luc2/LacZ ID7 (positive control) was performed in 96-well ViewPlate microplates (PerkinElmer ${ }^{\oplus}$, Waltman, USA). Cells were attached overnight and imaged on the IVIS Lumina II (PerkinElmer ${ }^{\oplus}$ ) following the addition of $150 \mu \mathrm{g} / \mathrm{ml}$ D-luciferin (Gold Biotechnology ${ }^{\circledR}$ St. Louis, USA). For quantification, a region of interest (ROI) was manually selected using the Living Image (Version 3.1) software. BLI intensity values were represented as the mean average radiance $\pm \mathrm{SD}\left(\mathrm{p} / \mathrm{s} / \mathrm{cm}^{2} / \mathrm{sr}\right)$.

2.10. In Vivo MSC Persistence. NOD $(n=4)$ and NOD/Scid $(n=4)$ mice (6-10 weeks of age) received a total of six subcutaneous (s.c.) injections of $1 \times 10^{4}(n=2), 1 \times 10^{5}(n=2)$, and $1 \times 10^{6}(n=2)$ midpassage MSC-Luc2 cells/mouse. Untreated age-matched NOD $(n=2)$ and NOD/Scid $(n=2)$ mice were utilized as negative controls. Mice were anaesthetised using $2.5 \%$ isoflurane carried in $\mathrm{O}_{2}(1.5 \mathrm{l} / \mathrm{min})$, transferred to the IVIS Lumina II imaging unit, and maintained under anaesthesia. BLI images were acquired $5 \mathrm{~min}$ after the intraperitoneal (i.p.) injection of D-luciferin $(15 \mathrm{mg} / \mathrm{ml})$ at $150 \mathrm{mg} / \mathrm{kg}$ or $10 \mu \mathrm{l} / \mathrm{g}$. For quantification, ROI was manually selected using the Living Image (Version 3.1) software. BLI intensity values were presented as the mean average radiance \pm standard errors of means (SEMs) $\left(\mathrm{p} / \mathrm{s} / \mathrm{cm}^{2} / \mathrm{sr}\right)$.

2.11. Construction of Lentiviral Plasmids. The pHMD and pHMD-INS-FUR lentiviral plasmids [3-5] were modified to express INS-FUR and the human codon-optimized murine (Mus musculus) Neurod1 and Pdx1 genes. Using GeneArt Gene Synthesis $^{\text {TM }}$ (Thermo Fisher ${ }^{\circledR}$, USA), murine Neurod 1 cDNA (NM_010894) was synthesized-linked to eGFP via a T2A peptide at the C-terminus. The Neurod1-T2A-eGFP sequence was PCR-amplified using the forward and reverse primers, $5^{\prime}$-GATACTTGGCCATATGACCAAATCATACA GCGA- $3^{\prime}$ and $5^{\prime}$-CCATGAGGCCCAGTTAAT- ${ }^{\prime}$, containing MscI and the PacI restriction sites, respectively. PCR-amplified Neurod1-T2A-eGFP was ligated into pHMD and pHMD-INS-FUR following digestion with MscI and PacI (New England Biolabs, Waltman, USA) to generate pHMD-Neurod 1 and pHMD-Neurod1/INS-FUR, respectively. 
The pAAV-Pdx1 plasmid (donated by Dr. Grant Logan, Children's Medical Research Institute, Westmead Children's Hospital, Sydney, Australia) containing the murine Pdx1 cDNA (NM_008814.3) and the fluorescent reporter mCherry upstream and downstream of the internal ribosomal entry site (IRES), respectively, was used to clone murine $P d x 1$ into the HMD lentiviral plasmid. The Pdx1-IRES-mCherry sequence was PCR-amplified using the forward and reverse primers, $5^{\prime}$-GATACTGGATCCAT GAACAGCGAGGAACAG-3' and $5^{\prime}$-GCGCCGTTAAT TAATTACTTGTACAGCTCGTC-3', containing BamHI and PacI restriction sites, respectively. PCR-amplified Pdx1-IRES-mCherry was ligated into pHMD following digestion with BamHI-HF ${ }^{\circledast}$ and PacI (New England Biolabs ${ }^{\circledR}$, USA) to generate $\mathrm{pHMD}-P d x 1$. Schematic representations of the cloned lentiviral plasmids are illustrated in Supplementary Figure $1 \mathrm{~b}$.

2.12. Lentiviral Vector Propagation and Titration. Lentiviral plasmids were cotransfected into HEK293T cells using calcium phosphate precipitation as previously described [3-5]. Lentiviral particles were harvested at $36,48,60$, and $72 \mathrm{~h}$ posttransfection, filtered through Millex-HV $0.45 \mu \mathrm{M}$ polyvinylidene fluoride syringe filters (EMD Millipore ${ }^{\odot}$, Burlington, USA), and concentrated using Amicon Ultra $100 \mathrm{kDa}$ filters (EMD Millipore ${ }^{\odot}$, USA). Concentrated lentiviral particles were titered using NIH3T3 cells and FACS analysis of eGFP and mCherry expression. Flow cytometry data were analyzed using BD FACSDiva ${ }^{\mathrm{TM}}$ software (Version 8.0.1).

2.13. Viral Transduction. Midpassage MSC-Luc2 $\left(1 \times 10^{5}\right.$ cells/well) were transduced overnight $(\mathrm{MOI}=10)$ with HMD, HMD-INS-FUR, HMD-Neurod1, HMD-Neurod1/INS-FUR, and HMD-Pdx1 in standard MSC medium supplemented with $8 \mu \mathrm{g} / \mathrm{ml}$ Polybrene (Sigma-Aldrich ${ }^{\mathrm{TM}}$, Australia). Following transduction, lentiviral particles were removed and the cells cultured for $72 \mathrm{~h}$, after which the cells were sorted into $\mathrm{eGFP}^{+}$and $\mathrm{mCherry}^{+}$populations at the Advanced Cytometry Facility (Centenary Institute, Sydney, Australia) using a BD FACSAria ${ }^{\mathrm{TM}}$ II and analysed using BD FACSDiva ${ }^{\mathrm{TM}}$ software (Version 6.1.3). Fluorescence imaging of positively transduced MSCs was performed using a Leica ${ }^{\circledR}$ DM microscope (Leica Microsystems ${ }^{\circledR}$, Australia).

2.14. Chronic and Acute Insulin Secretion. For chronic insulin secretion, untransduced and transduced MSCs $\left(1 \times 10^{5}\right.$ cells/well in triplicate, $n=4$ ) were cultured for $24 \mathrm{~h}$ in standard MSC medium. For glucose-stimulated insulin secretion, untransduced and transduced MSCs $\left(1 \times 10^{5}\right.$ cells/well in triplicate, $n=3$ ) were seeded in 6-well plates and sequentially stimulated with $20 \mathrm{mM}$ D-Glucose (Sigma-Aldrich ${ }^{\mathrm{TM}}$, Australia), as previously described [25]. The human insulin concentrations in harvested supernatants, from both chronic and acute insulin secretion assays, were quantified using the ARCHITECT $^{\mathrm{TM}}$ i4000SR Immunoassay Analyser (Abbott Diagnostics ${ }^{\circledR}$, Macquarie Park, Australia). Data were represented as mean insulin concentration $\left(\mathrm{pmol} / \mathrm{ml} / 1 \times 10^{5}\right.$ cells) \pm SD .
2.15. Induction of Diabetes in NOD/Scid Mice. NOD/Scid mice received $170 \mathrm{mg} / \mathrm{kg}$ of STZ in $0.1 \mathrm{M}$ sodium citrate buffer ( $\mathrm{pH} 4.0$ ) via i.p. injection. All animals, including nondiabetic controls, had their body weights and blood glucose concentrations measured daily using an Accu-Chek ${ }^{\circledR}$ Performa glucometer (Accu-Chek ${ }^{\circledR}$, Roche, Castle Hill, Australia). Animals that did not develop hyperglycaemia (blood glucose concentration $>8 \mathrm{mmol} / \mathrm{l}$ ) within 1 week post-STZ injection received a second low-dose $(40 \mathrm{mg} / \mathrm{kg})$ STZ injection. Animals that displayed hyperglycaemia for four consecutive days were considered diabetic and were used for in vivo experiments.

2.16. Transplantation of MSC in STZ-NOD/Scid Mice. Two groups of STZ-diabetic NOD/Scid mice received s.c. injections of $1 \times 10^{7}(n=6)$ and $5 \times 10^{7}(n=6)$ late passage INS-FUR-expressing MSCs, respectively. Nondiabetic $(n=6)$ and untreated diabetic $(n=6)$ animals were assessed alongside treated animals. Body weights and blood glucose concentrations were measured daily. Animals that displayed hypoglycaemia (blood glucose concentration $<3 \mathrm{mmol} / \mathrm{l}$ ) or body weight loss ( $>10 \%$ ) for two consecutive days were euthanized by $\mathrm{CO}_{2}$ asphyxiation and cervical dislocation.

2.17. Intraperitoneal Glucose Tolerance Test (IPGTT). Normal $(n=5)$ and treated $(n=3)$ mice fasted for $6 \mathrm{~h}$, were transferred to a ZDS Qube Manifold 5 Station (Advanced Anesthesia Specialists ${ }^{\circledR}$, Australia), and were maintained under stable anaesthesia $(2.5 \mathrm{l} / \mathrm{min}$ isoflurane and $1.5 \mathrm{l} / \mathrm{min} \mathrm{O}_{2}$ ). Mice received an i.p. injection of $2 \mathrm{~g} / \mathrm{kg}$ $50 \% \mathrm{v} / \mathrm{v}$ liquid glucose $(0.5 \mathrm{~g} / \mathrm{ml})$. Blood glucose was measured at $0,5,15,30,60$, and 90 min postinjection. Following IPGTTs, animals were euthanized by $\mathrm{CO}_{2}$ asphyxiation and cervical dislocation.

2.18. Statistical Analysis. All statistical analysis was performed using GraphPad Prism $7^{\circledast}$ software. Values were presented as means \pm SDs or SEMs. One-way or two-way ANOVA, with the appropriate posttests, was performed, with $p<0.05$ indicating significance.

\section{Results}

3.1. In Vitro Characteristics of NOD MSCs. MSCs identified by FACS were characterized by the surface marker profile CD $45^{-} / \mathrm{Ly}^{+}$and constituted $\sim 33 \%$ of the parental stromal cell population (Figure 1(a)). MSCs displayed the characteristic fibroblast-like morphology from early to late passage numbers (Figure 1(b)). However, a decrease in MSC diameter was observed with increasing passage, from $\sim 100 \mu \mathrm{m}$ (early passage) to $50 \mu \mathrm{m}$ (late passage). Although MSCs underwent a period of early passage replicative crisis during P5-8 (data not shown), MSCs continued to self-renew up to 60 passages (maximum culture period). An intrapopulation analysis of MSC proliferation and clonogenicity showed no significant difference in proliferation (Figure 1(c)) and conservation of clonogenicity potency (Figure 1(d)) from early to late passage numbers. 


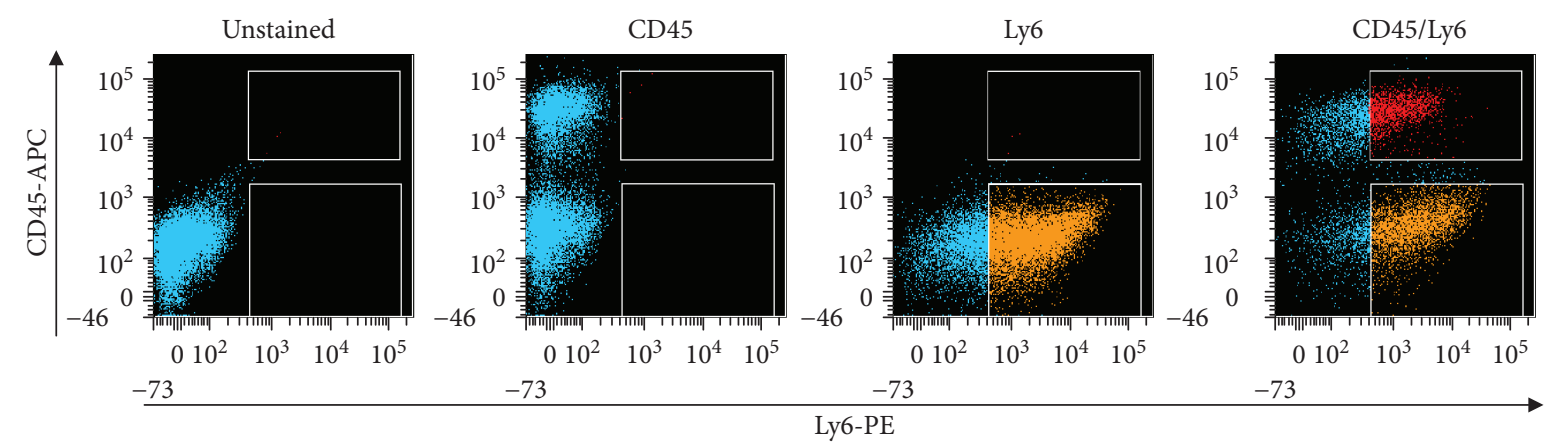

(a)
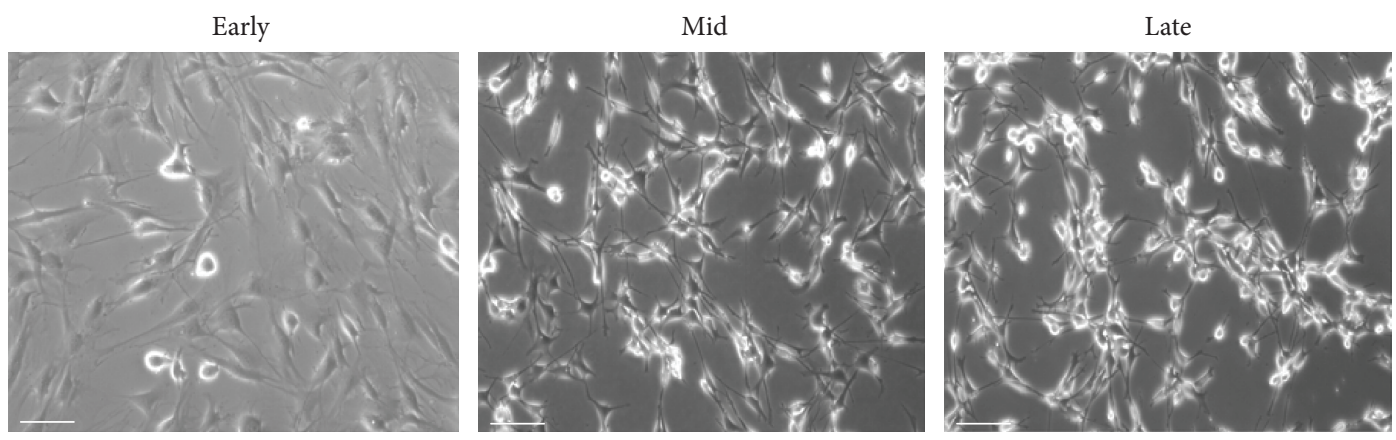

(b)

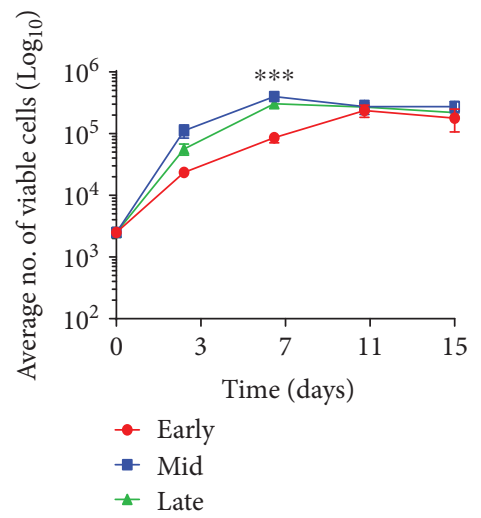

(c)

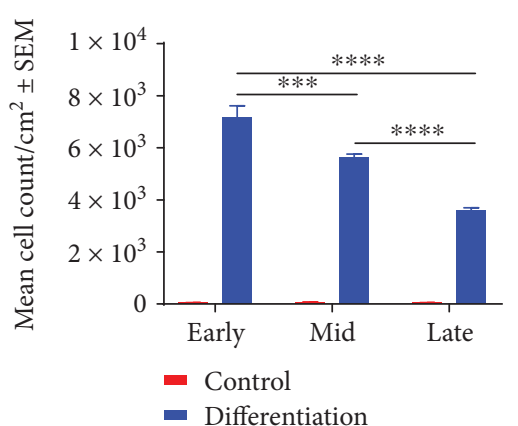

(e)

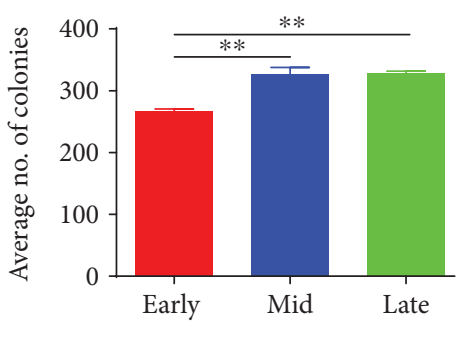

(d)

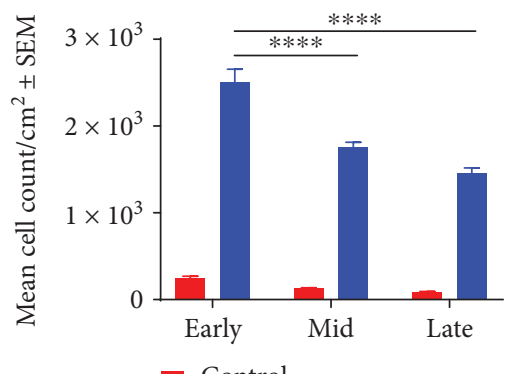

- Control

- Differentiation

(f)

FIgURE 1: Continued. 


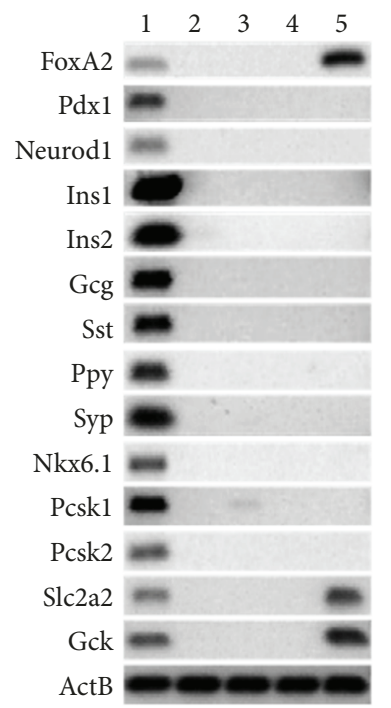

(g)

FIGURE 1: In vitro characteristics of NOD-derived MSCs with cell culture expansion. (a) FACS analysis and enrichment of NOD-derived MSCs. Following culture for two passages, NOD bone marrow stromal cells were stained with nil antibody (unstained), CD45 mAb conjugated to fluorochrome APC (CD45-APC), Ly6 MAb conjugated to fluorochrome PE (Ly6-PE), and both mAbs (CD45-APC/Ly6-PE). Fluorescence dot plots of CD45-APC ( $y$-axis) and Ly6-PE ( $x$-axis) were used to identify the MSC (CD45/Ly6 ${ }^{+}$; orange) and double-positive $\left(\mathrm{CD} 45^{+} / \mathrm{Ly}^{+}\right.$; red) cell subpopulations ready for cell sorting using the BD FACSAria ${ }^{\mathrm{TM}}$ II instrument. Representative of three individual FACS experiments. (b) Plastic adherence, fibroblast-like morphology, and self-renewal without differentiation into other cell types. MSCs maintained fibroblast-like morphology as assessed using light microscopy (Leica DM microscope; 10x magnification; scale bar $=100 \mu \mathrm{M}$ ). (c) Improved cell proliferation with culture expansion. Data are presented as mean viable cells \pm SDs $(n=3)$. A two-way ANOVA with Tukey's posttests was performed, ${ }^{*} p<0.05$. (d) Improved fibroblastic colony formation following methylene blue staining. Data are presented as mean number of colonies \pm SEMs $(n=3)$. A one-way ANOVA and Tukey's posttests were performed, ${ }^{*} p<0.05$. (e) Semiquantitative analysis of adipogenic differentiation under defined conditions. NOD-derived MSCs maintained fat formation following Oil Red O staining, albeit at reduced levels, with increasing passage number. Data are presented as mean cell count $/ \mathrm{cm}^{2} \pm \operatorname{SEM}(n=3)$. A two-way ANOVA and Tukey's posttests were performed, ${ }^{*} p<0.05$. (f) Semiquantitative analysis of osteogenic differentiation under defined conditions. NOD-derived MSC maintained bone formation following Alizarin Red staining, albeit at lower levels, with increasing passage number. Data are presented as mean cell count $/ \mathrm{cm}^{2} \mathrm{SEM}(n=3)$. A two-way ANOVA and Tukey's posttests were performed, ${ }^{*} p<0.05$. (g) Pancreatic transcription factor and hormone and protein expression levels were determined by RT-PCR. MSCs did not express any transcription factors, hormones, or protein found in the pancreas. Positive control mouse pancreas (lane 1), plastic-adherent MSCs (lane 2), plastic-adherent hematopoietic cells (lane 3), adherent bone marrow cells (lane 4), and negative control mouse liver (lane 5).

To demonstrate that NOD MSCs underwent trilineage differentiation, as defined by the International Society Cell and Gene Therapy (ISCT), trilineage differentiation assays were performed at early, mid, and late passage numbers. NOD MSC demonstrated trilineage differentiation into adipocytes (Supplementary Figure 2), osteocytes (Supplementary Figure 3), and chondrocytes (Supplementary Figure 4). Semiquantitative analysis of adipogenesis and osteogenesis was assessed by scoring the degree of differentiation, as previously described [24]. MSCs displayed reduced adipogenesis (Figure 1(e)) and osteogenesis (Figure 1(f)) with increasing passage number.

To confirm that MSCs did not intrinsically express any pancreatic transcription factors or hormones, RT-PCR analyses were performed and showed a lack of expression of pancreatic transcription factors, hormones, and proteins in all adherent bone marrow cell populations (Figure $1(\mathrm{~g})$ ). As expected, all genes were expressed in normal mouse pancreas (positive control), and FoxA2, Scl2a2, and Gck were expressed in normal mouse liver (negative control).
3.2. Syngeneic MSCs Are Cleared in an Immune-Competent Animal Model. Noninvasive BLI is an established and sensitive tool for assessing cell replacement therapy safety and efficacy in living preclinical small animal models. Furthermore, preclinical BLI results often serve as the decision point of the suitability of a cell replacement therapy for clinical trial testing in humans. This study utilized the Firefly luciferase reporter gene, $L u c 2$, a $L u c 2$-specific light-producing substrate D-luciferin, and an IVIS Lumina II imaging system (Perkin Elmer ${ }^{\odot}$ ). Prior to performing in vitro and in vivo BLI, a clonal population of MSCs expressing Luc2 (MSC-Luc2) was obtained by selection with Hygromycin B. MSC-Luc2 retained a fibroblast-like morphology similar to that observed for parental MSCs (Figure 2(a)); however, these cells exhibited a reduced cell diameter $(\sim 100 \mu$ m nucleofected versus $150 \mu \mathrm{m}$ parental). In vitro analyses of BLI at multiple time points over a 3-hour period (Figure 2(b)), in combination with linear regression analysis (Figure 2(c)), confirmed that a clonal population of MSC-Luc2 had been selected and that bioluminescence was stable for up to $3 \mathrm{~h}$ in vitro. 

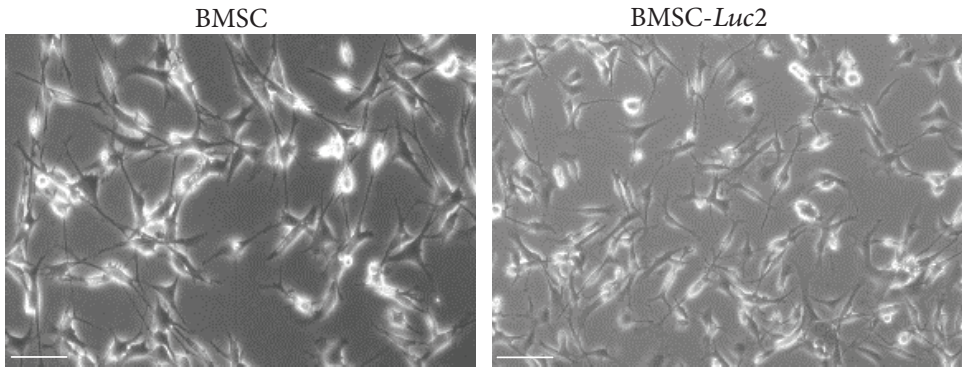

(a)

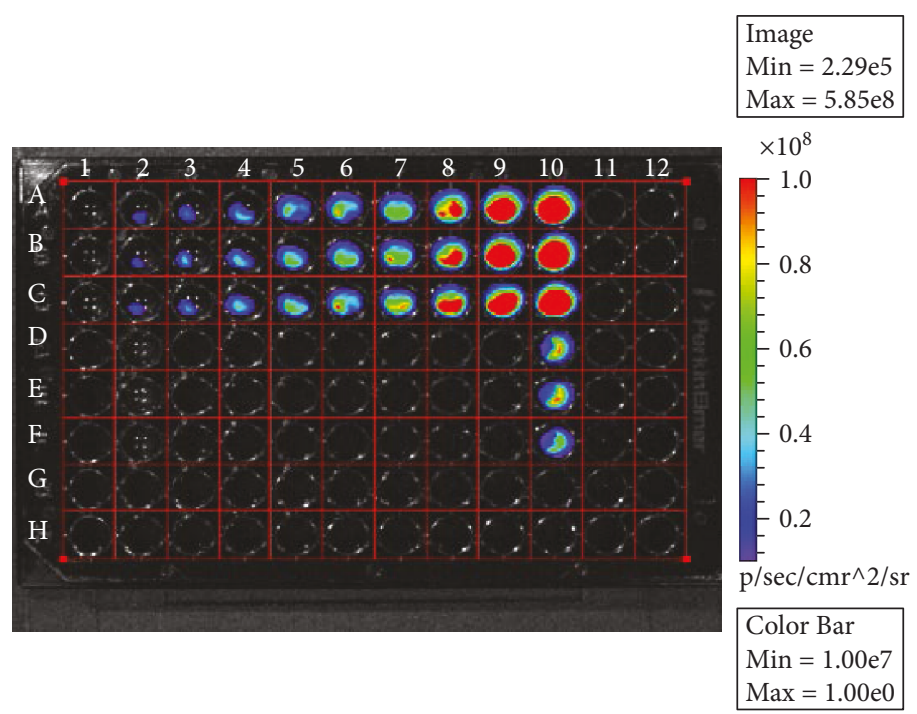

(b)

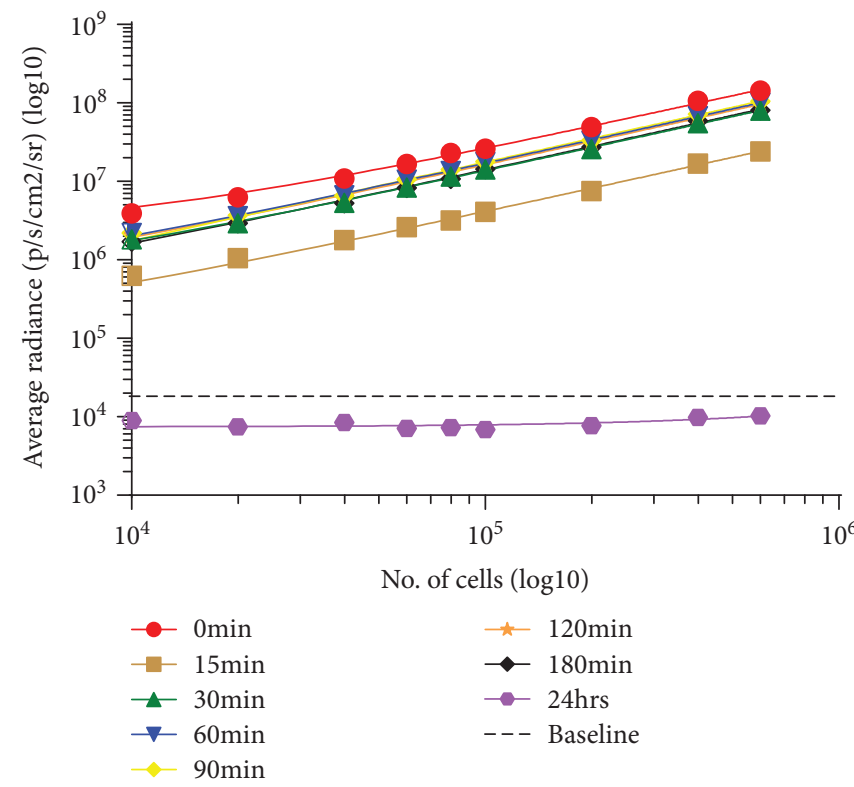

(c)

FIGURE 2: NOD-derived MSC nucleofection. (a) MSCs (early passage number) were nucleofected with 0 and $5 \mu$ g pVITRO2-Luc2. Parental MSCs and MSC-Luc2 at an equivalent passage number (P15) showed native fibroblast-like morphology and maintained plastic adherence and self-renewal properties. Images were acquired on a Leica DM light microscope at 10x magnification, scale bar $=100 \mu \mathrm{m}$. (b) In vitro functional characterization of luciferase activity in MSC- $L u c 2$. Cells were incubated with $1: 1 \mathrm{D}$-luciferin $(300 \mu \mathrm{g} / \mathrm{ml})$ and imaged on the IVIS Lumina II, according to the in vitro BLI acquisition settings. The image represented is at $t=30 \mathrm{~min}$ after the addition of D-luciferin. Lane 1 : D-PBS; lanes 2-10: MSC-Luc2 and MSC- Luc2/LacZ (control). (c) Linear regression analysis of luminescent signal was performed using GraphPad Prism $7^{\circledR}$. Data are presented as means \pm SDs of triplicates. 

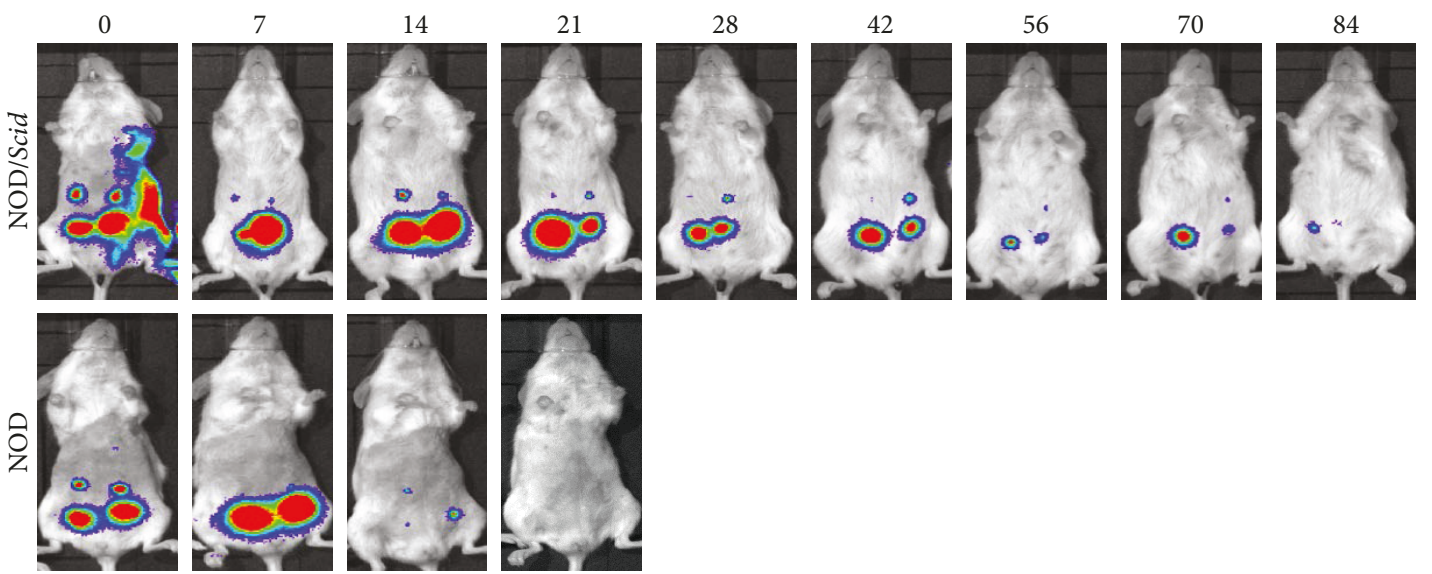

Min $=-5.75 e 4$

$\operatorname{Max}=2.84 \mathrm{e} 6$

$\times 10^{6}$

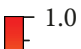

$-0.8$

$-0.6$

0.4

0.2

$\mathrm{p} / \mathrm{sec} / \mathrm{cm}^{\wedge} 2 / \mathrm{sr}$

\begin{tabular}{|l|}
\hline Color Bar \\
Min $=1.00 \mathrm{e} 5$ \\
Max $=1.00 \mathrm{e} 6$
\end{tabular}

(a)
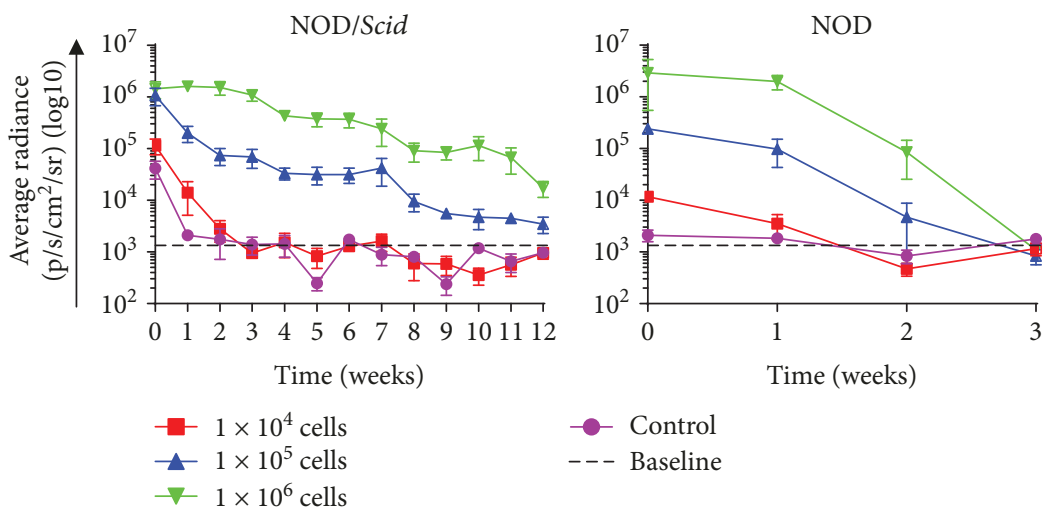

(b)

Figure 3: Persistence of syngeneic MSCs in immune-competent and immune-deficient animal models. (a) NOD ( $n=4)$ and NOD/Scid $(n=4)$ mice (6-10 weeks of age) received a total of six subcutaneous (s.c.) injections of $1 \times 10^{4}(n=2), 1 \times 10^{5}(n=2)$, and $1 \times 10^{6}(n=2)$ midpassage MSC-Luc2 cells/mouse. Untreated age-matched NOD $(n=2)$ and NOD/Scid $(n=2)$ mice were utilized as negative controls. BLI images were acquired following i.p. administration of D-luciferin $(15 \mathrm{mg} / \mathrm{ml})$ at $150 \mathrm{mg} / \mathrm{kg}$ or $10 \mu \mathrm{l} / \mathrm{g}$. Images are representative of a single experimental NOD/Scid and NOD animal. (b) Analysis of MSC BLI in NOD and NOD/Scid mice. Regions of interest were established surrounding the areas corresponding to the sites of cell transplantation using the Living Image 3.1 (PerkinElmer ${ }^{\mathrm{TM}}$ ) software. Quantitative data were subsequently analyzed using GraphPad Prism $7^{\circledR}$. Data were presented as mean radiance \pm SEM over time (weeks). A two-way ANOVA and Tukey's posttests were performed, ${ }^{*} p<0.05$.

We chose to assess the persistence of MSCs transplanted subcutaneously in immune-competent NOD and immune-deficient NOD/Scid animal models as this most closely reflects the route of administration of a cell replacement therapy for individuals with T1D. Thus, MSC-Luc2 were transplanted subcutaneously at multiple cell concentrations to determine the lowest cell concentration and the length of time for which bioluminescence could be detected (Figure 3(a)). Quantitative analysis of BLI data showed that in both NOD/Scid and NOD mice there was an increase in bioluminescence with increasing cell dose (Figure 3(b)), which resulted in a dose-dependent increase in persistence of bioluminescence in both animal models (Supplementary Tables 2A and 2B). Bioluminescence, albeit diminished, could be detected in NOD/Scid mice for up to 12 weeks, suggesting poor survival of MSCs at the s.c. transplant site. By comparison, bioluminescence persisted for 2 weeks in NOD mice, after which signal could no longer be detected, suggesting an immune-mediated clearing of the MSC graft. In fact, upon challenge with a follow-up injection of $1 \times 10^{6}$ MSCs, clearing of the MSC graft occurred within 1 week postinjection (data not shown). These kinetics are consistent with the generation of memory $\mathrm{T}$ cell populations stimulated after the initial exposure to MSCs. 
3.3. Neurod1 and Pdx1 Fail to Induce $\beta$-Cell Differentiation of Ex Vivo Expanded NOD MSCs. The pancreatic transcription factors, Neurod 1 and Pdx1, were overexpressed in MSC-Luc2 to function as mediators of pancreatic transdifferentiation, whilst the INS-FUR gene was overexpressed to allow for mature human insulin production. Transduced MSCs were analysed via FACS and sorted into individual populations, as outlined in Supplementary Tables 3A and 3B. The sorted MSCs were returned to culture and imaged for eGFP and mCherry expression 7 days posttransduction (Figures 4(a) and 4(b)). As can be seen, eGFP expression in MSCs transduced with Neurod1 and INS-FUR/Neurod1 was lower than that in cells transduced with the existing HMD and HMD-INS-FUR lentiviral vectors, a consequence of lower viral titers.

Transduced MSCs were subsequently cultured for a period of 28 days, at which point morphological analysis of the differentiation process was performed (Figure 4(c)). Transduced MSCs expressing both murine Neurod1 and $P d x 1$ alone, or in combination with INS-FUR, retained a fibroblast-like morphology in comparison to their untransduced counterparts, demonstrating that no change in morphology was attributable to transgene overexpression.

Gene expression profiling was performed to determine if ectopic expression of Neurod1, Pdxl, and INS-FUR in ex vivo expanded MSCs resulted in pancreatic differentiation. As can be seen in Figure 4(d), exogenous murine Neurod1 was detected at 28 days posttransduction in MSCs transduced with HMD-Neurod1 and HMD-INS-FUR/Neurod1, and as expected, expression was not detected in the parental MSCs, MSCs transduced with HMD and HMD-INS-FUR, and the positive control (mouse pancreas). Interestingly, exogenous Neurod 1 expression resulted in the expression of endogenous Neurod1, suggesting a potential autoregulatory function of Neurod1. However, Pdx1, Nkx6.1, Scl2a2, Ins1, and Ins2 were not detected in parental and transduced MSCs. In Figure 4(e), a similar pattern of gene expression was observed following the ectopic expression of murine $P d x 1$, as was observed with ectopic expression of Neurod1, with the exception that ectopic $P d x 1$ did not result in endogenous $P d x 1$ expression. Together, these data confirm the lack of pancreatic differentiation in ex vivo expanded MSC expressing Neurod1 and $P d x 1$.

3.4. Gene-Modified Ex Vivo Expanded NOD MSCs Demonstrate Abnormal Glucose-Stimulated Insulin Secretion. The ability of transduced MSCs to secrete mature insulin in vitro in response to glucose stimulation was determined. A significant quantity of mature insulin $\left(\sim 4.5 \mathrm{pmol} / \mathrm{ml} / 1 \times 10^{5}\right.$ cells $)$ was detected in the medium of MSCs expressing INS-FUR alone and in combination with $P d x 1$. By comparison, untransduced MSCs and MSCs transduced with empty vector or Neurodl alone did not secrete mature insulin (Figure 4(f)). There was also a significant difference $(p<0.005)$ in the quantity of insulin secreted between MSC-INS-FUR $\left(\sim 4.5 \mathrm{pmol} / \mathrm{ml} / 1 \times 10^{5}\right.$ cells $)$ and MSC-INS-FUR/Neurod1 $\left(\sim 0.3 \mathrm{pmol} / \mathrm{ml} / 1 \times 10^{5}\right.$ cells), which directly correlated with differences in the expression of the fluorescent reporter. Acute glucose stimulation assays showed that following stimulation with $20 \mathrm{mM}$ D-Glucose, glucose-stimulated insulin secretion (GSIS) was not present (Figure $4(\mathrm{~g})$ ). The absence of GSIS was expected due to the lack of Slc2a2 expression, as detected by RT-PCR.

\subsection{INS-FUR-Expressing MSCs Fail to Restore} Normoglycaemia in STZ-Diabetic NOD/Scid Mice. To determine if INS-FUR-expressing MSCs could restore normoglycaemia in STZ-diabetic NOD/Scid mice, animals received a s.c. transplant of either $1 \times 10^{7}$ or $5 \times 10^{7}$ cells. In animals treated with $5 \times 10^{7}$ cells, within $24 \mathrm{~h}$ following transplantation, there was a decrease in blood glucose concentrations, and a significant $(p<0.05)$ decrease was observed at days 8 and 12 posttransplantation (Figure 5(a)). In addition, there was a significant decrease in the blood glucose levels of the animals treated with $5 \times 10^{7}$ cells, from before to after transplantation, for a period of $\sim 15$ days (pretransplant vs. posttransplant, $p<0.05$ ) (Supplementary Tables $4 \mathrm{~A}$ and $4 \mathrm{~B})$. By comparison, blood glucose concentrations in diabetic animals and animals treated with $1 \times 10^{7}$ cells remained significantly higher $(p<0.0001)$ than those in the normal controls for the duration of the experiment. Most importantly, animals treated with either $1 \times 10^{7}$ or $5 \times 10^{7}$ cells did not normalize blood glucose concentration at any time for the duration of the experiment. In addition, there was a significant difference in the body weights of treated animals in comparison to normal controls both before and after transplantation, despite random allocation of animals to the different groups (Figure 5(b)). However, at no time point was there a significant decrease in body weight observed over the time course of the experiment.

Prior to euthanasia, animals treated with $5 \times 10^{7}$ cells $(n=3)$ were assessed for glucose tolerance via an IPGTT. Treated animals displayed an abnormal glucose tolerance in comparison to normal controls (Figure 5(c)). The high degree of variation in the glucose tolerance observed for the treatment group was due to one treated animal beginning the IPGTT at a significantly lower blood glucose concentration than the other treated animals, a consequence of the cell transplant having successfully reduced blood glucose levels in this animal.

\section{Discussion}

Stem cells are characterized by two defining long-term characteristics: (i) the ability for renewal without differentiation into other cell types when cultured under standard conditions and (ii) the continued potential to develop into specialized cell types when cultured under defined experimental conditions. The early, mid, and late passage number NOD-derived MSCs utilized in this study fulfilled the ISCT criteria of plastic adherence, self-renewal, and colony formation without differentiation into other cell types under standard MSC culture conditions and trilineage mesenchymal differentiation into bone, fat, and cartilage under defined cell culture conditions $[20,21]$.

In this study, NOD-derived MSCs maintained a fibroblast-like morphology, potent self-renewal, and clonogenicity throughout early, mid, and late passage numbers. 

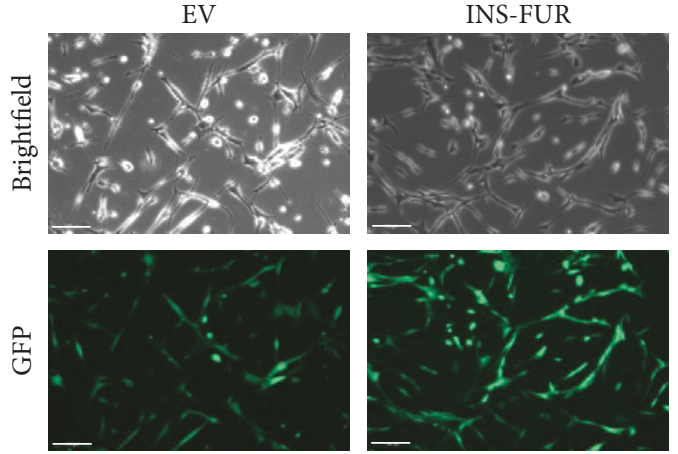

(a)
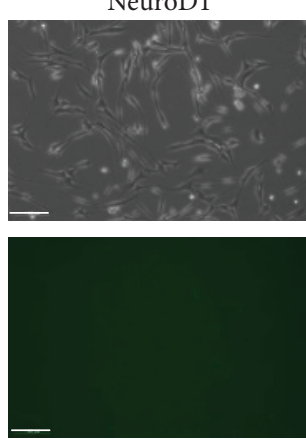
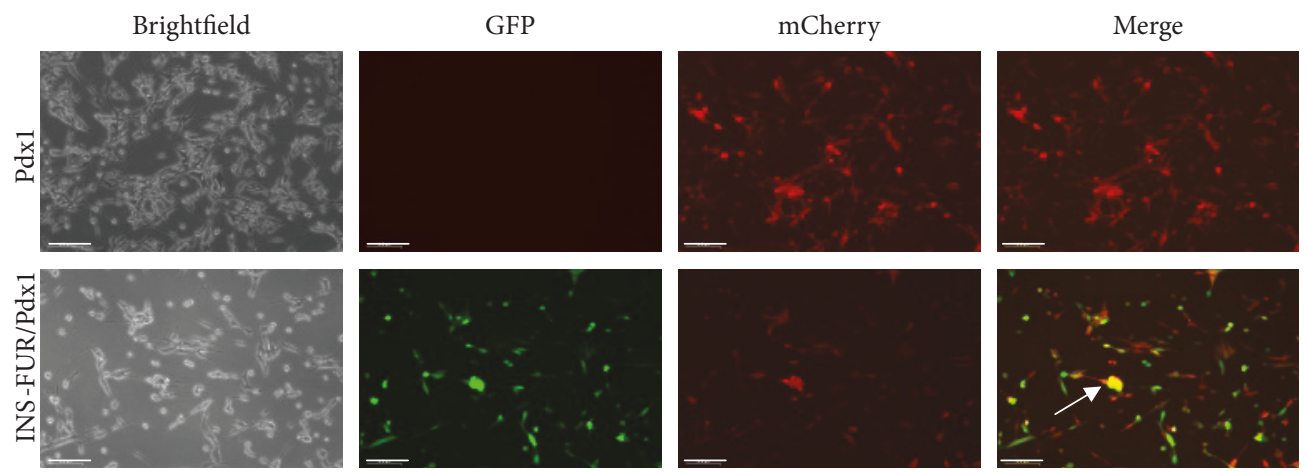

(b)
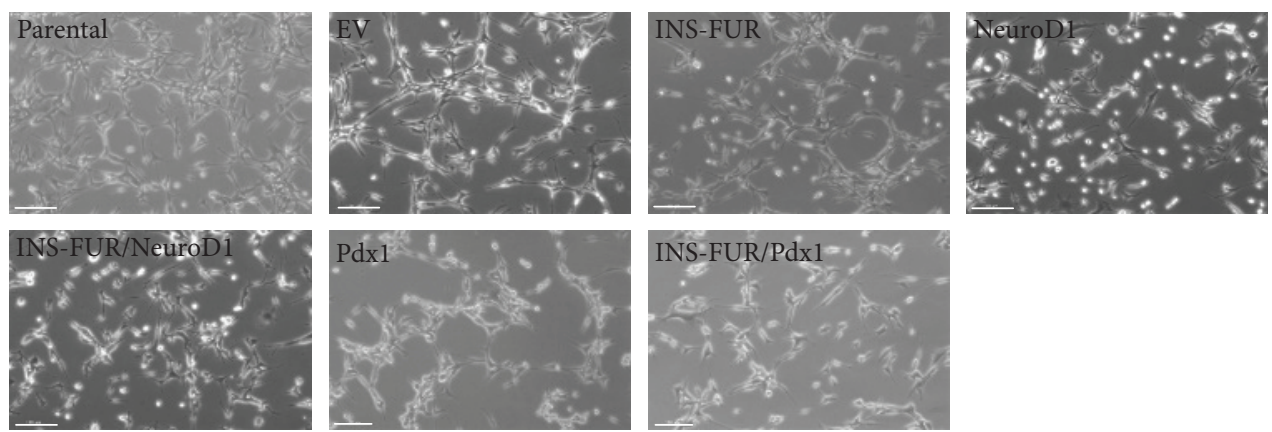

(c)

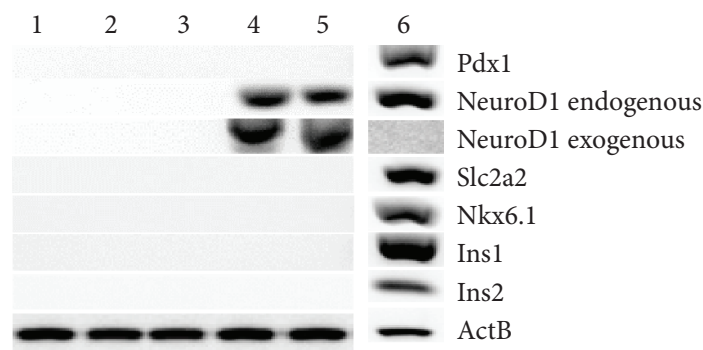

(d)

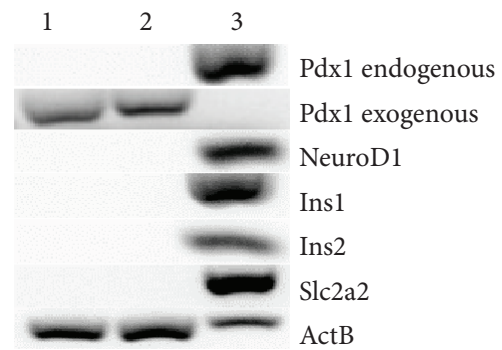

(e)

Figure 4: Continued. 


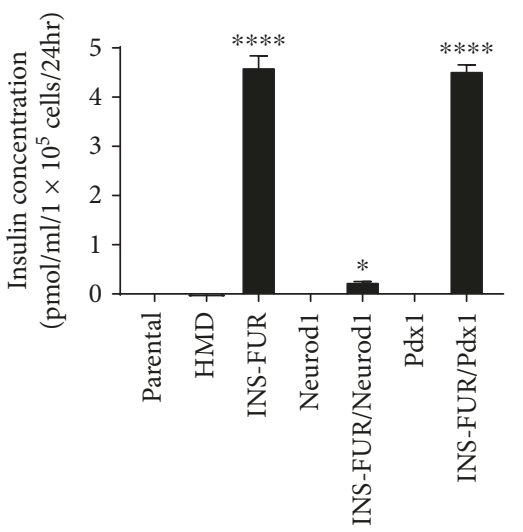

(f)

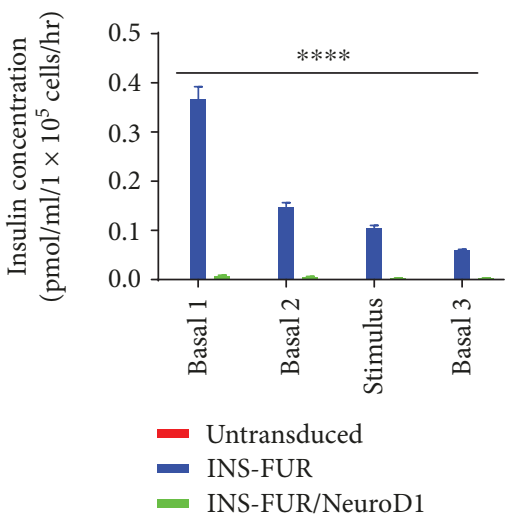

(g)

Figure 4: Analysis of INS-FUR-, Neurod1-, and Pdx1-transduced MSC. (a) Fluorescence imaging of MSCs transduced with empty vector (EV), Neurod1, and INS-FUR. Transduced cells were returned to culture after sorting for GFP positivity and imaged for GFP expression (day 7 posttransduction) using a Leica DM fluorescence microscope (Leica Microsystems), 10x magnification with bright field and GFP fluorescence filter sets; scale bar $=100 \mu \mathrm{m}$. (b) Fluorescence imaging of MSCs and MSC-INS-FUR transduced with Pdx1. Transduced cells were returned to culture post sorting and imaged for GFP and mCherry expression (day 7 posttransduction) using a Leica DM microscope, 10x magnification under bright field, GFP and Texas Red fluorescence filter sets; scale bar $=100 \mu \mathrm{m}$. (c) Morphological characterization of MSCs posttransduction. Bright-field images were acquired at 28 days posttransduction on a Leica DM microscope (Leica Microsystems) at 10x magnification under bright-field setting; scale bar $=100 \mu \mathrm{m}$. (d) Gene expression profiling of INS-FUR and Neurod1-expressing MSC. Lane 1: untransduced MSC; lane 2: MSC-EV; lane 3: MSC-INS-FUR; lane 4: MSC-Neurod1; lane 5: MSC-INS-FUR/Neurod1, and lane 6: mouse pancreas (positive control). (e) Gene expression profiling of Pdx1-expressing MSCs. Lane 1: MSC-Pdx1; lane 2: MSC-INS-FUR/Pdxl; and lane 3: mouse pancreas (positive control). (f) Chronic insulin secretion from transduced MSCs. Human insulin was quantified using the ARCHITECT $^{\text {тM }}$ i4000SR Immunoassay Analyser (Abbott Diagnostics $\left.{ }^{(}\right)$. Data are represented as means \pm SDs $(n=4)$. A one-way ANOVA with Sidak's posttests were performed, ${ }^{*} p<0.05$. (g) Acute glucose-stimulated insulin secretion from INS-FUR- and Neurod1-transduced MSCs. Human insulin was quantified using the ARCHITECT ${ }^{\mathrm{TM}}$ i4000SR Immunoassay Analyser (Abbott Diagnostics ${ }^{\odot}$ ). Data were presented as means \pm SDs $(n=3)$. Two-way ANOVA with Tukey's posttests were performed, ${ }^{*} p<0.05$.

This finding is in contrast to previous studies, which suggest that MSCs undergo age-related changes with continued cell passage [26-28]. The maintenance of a fibroblast-like morphology can be attributed, in part, to medium supplementation with bFGF. These results are supported by another study, where bFGF inhibited apoptosis and promoted proliferation of MSCs through a reduction in cellular oxidative stress [29]. Although MSC characteristics of self-renewal and colony-forming units (CFU-F) were conserved following cell culture expansion, MSCs showed some reduction in trilineage differentiation with increasing passage, which is in concordance with other studies [30-32]. Furthermore, several studies have demonstrated the detrimental effect of aging on multipotential differentiation, proliferation, and senescence $[31,33,34]$. Collectively, these findings highlight the importance of ongoing surveillance of stem cell-like properties, amongst other defining characteristics, when engineering replacement cell therapies.

To clarify whether NOD-derived MSCs were immune-evasive, we subcutaneously transplanted syngeneic MSCs into immune-competent NOD mice, which were detectable by BLI up to 14 days posttransplantation. In a similar study, MSCs that were transduced to coexpress luciferase and GFP, subsequently transplanted via the kidney artery in $\mathrm{BALB} / \mathrm{c}$ mice, were detected via BLI up to 14 days posttransplantation [35]. This demonstrates that the site of cell administration in immune-competent models does not affect cell survival and that syngeneic MSCs do not appear to be immune-privileged [36]. This may be due to several factors, including the overexpression of the nonmammalian Luc2 transgene and contaminating FBS, factors that may override the inherent immune privilege characteristics of MSCs. In fact, previous studies have demonstrated that sustained high levels of luciferase expression induce luciferase-specific immune responses in immune-competent animal models, thereby limiting the utility of luciferase as an in vivo reporter in transplantation studies [37, 38].

However, in immune-deficient NOD/Scid mice, syngeneic MSCs were detected for a significantly longer period (up to 12 weeks posttransplantation), albeit with diminishing persistence. These results are supported by similar studies, which show loss of transplanted MSCs in immune-deficient animal models [39-41]. The current study highlights the importance of reporter gene selection and the limited timeframe in which MSC therapeutic effects can be evaluated, in both immune-competent and immune-deficient animal models. Assessment of MSCs in short-term studies has demonstrated their protective benefits [42], whereas long-term studies show little or no protection [43], which may be attributable to their lack of persistence in immune-competent models.

We also assessed the ability to differentiate ex vivo expanded MSCs into surrogate $\beta$-cells. Considering the success of Neurod 1 as a mediator of $\beta$-cell differentiation in nonpancreatic tissues, we sought to determine the potential of Neurod1 to induce $\beta$-cell differentiation of MSCs. In 


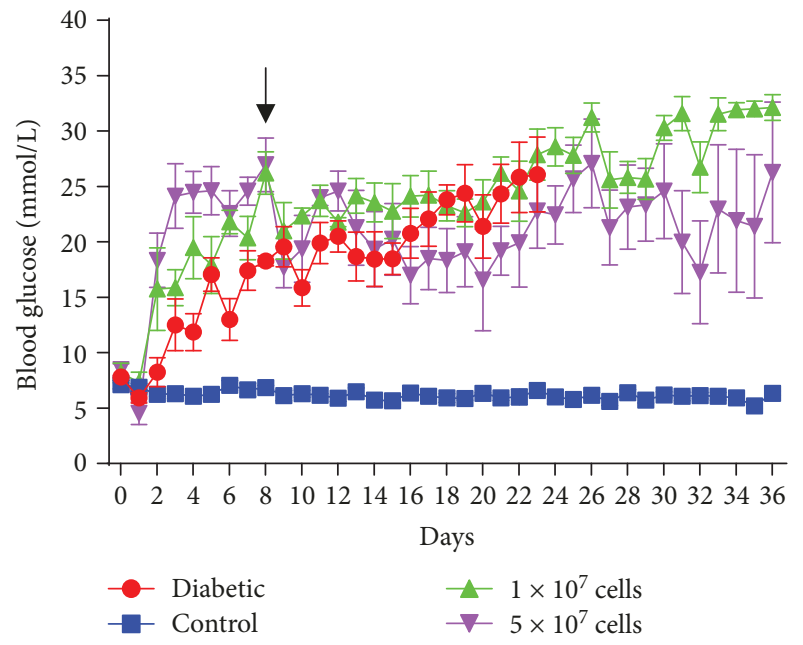

(a)

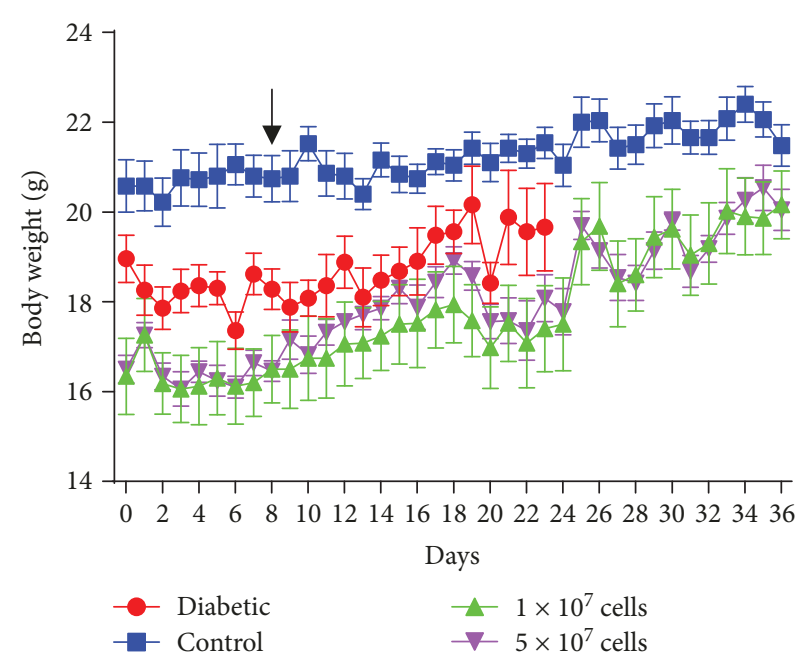

(b)

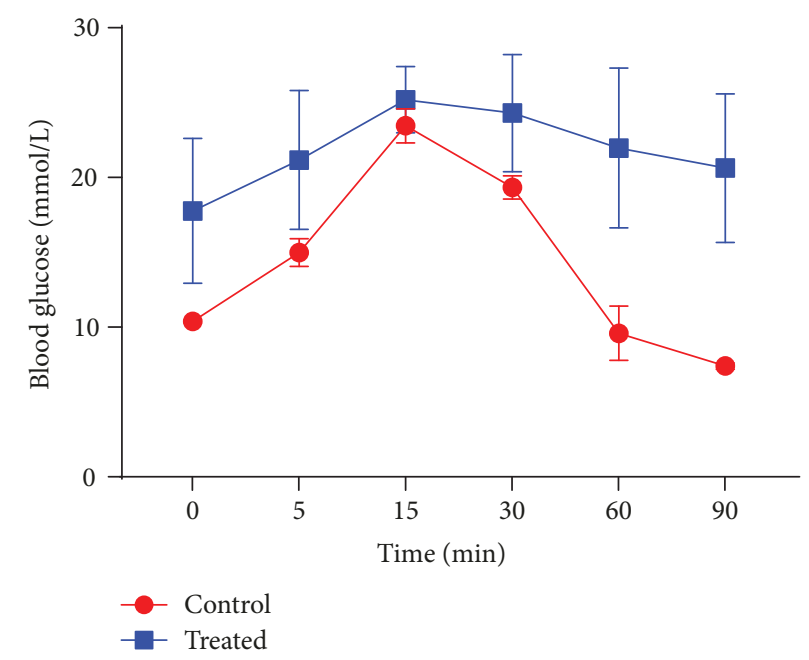

(c)

FIGURE 5: Transplantation of MSC-INS-FUR in STZ-diabetic NOD/Scid mice. (a) Blood glucose concentrations of treated STZ-diabetic NOD/Scid mice. Blood glucose measurements were recorded daily post-STZ injection for the duration of the experiment (36 days). Data were presented as means \pm SEMs $\left(n=6\right.$ mice per group). Two-way ANOVA with Sidak's posttests were performed, ${ }^{*} p<0.05$. (b) Body weights of treated STZ-NOD/Scid mice. Body weight measurements were recorded daily post-STZ injection for the duration of the experiment (36 days). Data were presented as means \pm SEMs ( $n=6$ mice per group). Two-way ANOVA was performed with Sidak's posttests, ${ }^{*} p<0.05$. (c) IPGTT in treated STZ-diabetic NOD/Scid mice. Blood glucose measurements were obtained at $0,5,15,30,60$, and 90 min post-D-Glucose injection. Data were presented as means \pm SEMs ( $n=5$, normal; $n=3$, treated). Two-way ANOVA with Sidak's posttests were performed, ${ }^{*} p<0.05$.

transduced MSCs, overexpression of Neurod1 and INS-FUR did not result in the cuboidal morphological changes associated with $\beta$-cell differentiation. In addition, gene expression profiling confirmed a lack of $\beta$-cell differentiation due to the absence of expression of endogenous pancreatic transcription factors and insulin. A recent study by Qing-Song et al. assessed the effect of Pdx1, Neurod1, and MafA overexpression in MSCs and showed that Neurod1 was a weak inducer of endogenous $P d x 1$ and Ins2 expression and that only in combination with $P d x 1$ and MafA was there a significant induction of $\beta$-cell differentiation and insulin expression [44]. Surprisingly, in this study, the lack of $\beta$-cell differentiation following overexpression of $P d x 1$ in culture-expanded MSCs indicated that ex vivo expansion results in defects in the pancreatic differentiation potential of MSCs.

A previous study showed that in vivo transplantation is required for functional $\beta$-cell maturation [45]; therefore, INS-FUR-expressing MSCs were assessed for their ability to reverse diabetes following transplantation into STZ-diabetic NOD/Scid mice. Upon transplantation of $5 \times 10^{7}$ INS-FUR-expressing MSCs, blood glucose concentrations decreased from 25-30 to $15-20 \mathrm{mmol} / \mathrm{l}$. However, at no time point did blood glucose levels fall within the normal physiological range $(5-7 \mathrm{mmol} / \mathrm{l})$. This is likely due to the severe hyperglycaemia induced in these animals, which likely requires higher cell numbers to restore blood glucose levels to within the normal physiological range. Despite this, there was a significant 
decrease in the blood glucose levels of treated vs. diabetic animals $(p<0.05)$ that was maintained for $\sim 2$ weeks; after which, blood glucose concentrations began to increase to pretransplant values. The subsequent increase in blood glucose concentrations of treated animals correlated with the results of the MSC persistence studies in NOD/Scid mice. In addition, IPGTTs of transplanted animals showed that they exhibited abnormal glucose tolerance, indicating a lack of in vivo GSIS. This finding corroborated the in vitro characterization studies.

In conclusion, the results of this study highlight several caveats to MSC-based gene therapy for T1D, which warrant careful consideration prior to the formulation of clinical trials. Considering that overexpression of $P d x 1$ in early-passage MSCs results in pancreatic differentiation [14], these data show that ex vivo expansion impairs pancreatic differentiation of NOD-derived MSCs through the age-related loss of multipotency. Therefore, gene modification should be performed as soon as practicable after the isolation of MSCs [46]. In addition, given that ex vivo expansion is required to generate sufficient quantities of adult-derived MSCs for therapeutic purposes and that this process impairs their therapeutic potential, the use of embryonic stem cells or induced pluripotent stem cells as an unlimited stem cell source may overcome this limitation $[47,48]$.

\section{Data Availability}

The data used to support the findings of this study are available from the corresponding author upon request.

\section{Disclosure}

Dario Gerace's current address is Department of Stem Cell and Regenerative Biology, Harvard Stem Cell Institute, Harvard University, Cambridge, MA, USA. Some of the data described in this manuscript were presented at the 77th Scientific Sessions of the American Diabetes Association 2017 (Gerace et al. "Ex vivo expanded murine mesenchymal stem cells as targets for the generation of a cell replacement therapy for Type 1 diabetes") and at the Australian Diabetes Society and Australian Diabetes Educators Association Annual Scientific Meeting 2017 (Simpson et al. "Issues with engineered ex vivo expanded murine mesenchymal stem cells as a cell replacement therapy for type 1 diabetes").

\section{Conflicts of Interest}

The authors declare that there are no conflicts of interest that could be perceived as prejudicing the impartiality of the research reported.

\section{Authors' Contributions}

DG was responsible for the conception and design, collection and presentation of data, data analysis and interpretation, and manuscript writing. RMW was responsible for conception and design. DG and RMW performed MSC isolations.
RMW performed MSC nucleofection, data analysis and interpretation, manuscript writing, and final approval of the manuscript. $\mathrm{RH}$ performed chondrogenesis assays. BR, $\mathrm{NTN}$, and $\mathrm{BOB}$ contributed to the study design and data analysis and interpretation. AMS was responsible for the financial support, conception and design, data analysis and interpretation, manuscript writing, and final approval of the manuscript. All authors read and approved the final manuscript.

\section{Acknowledgments}

The research was supported by project grants from the Diabetes Australia Research Trust (DART) and the Rebecca L. Cooper Medical Research Foundation. An Australian Postgraduate Award and a scholarship from the Arrow Bone Marrow Transplant Foundation supported DG. RH was supported by a UTS Research Excellence PhD Scholarship and UTS Top-up Scholarship from the Translational Cancer Research Network (TCRN). The authors are grateful to Frank Kao and Steven Allen (Advanced Cytometry Facility, Centenary Institute, Sydney, Australia) for their assistance with FACS sorting and also to Fiona Ryan and Lalit Overlunde for animal husbandry and assistance with animal health monitoring (University of Technology Sydney, Australia).

\section{Supplementary Materials}

Supplementary Figure 1: schematic of mammalian and lentiviral expression plasmid. (a) The luciferase gene was excised from pGL4.20 (Luc2/Puro) plasmid and subcloned into MCS1 of pVITRO2-hygro-mcs to generate the bioluminescent plasmid pVITRO2-Luc2. (b) The lentiviral plasmids HMD and HMD-INS-FUR were existing plasmids from a previous study. The Neurod1-T2A-eGFP sequence was subcloned to replace the existing eGFP sequence in the HMD and HMD-INS-FUR plasmids to generate HMD-Neurod1 and HMD-INS-FUR/Neurod1, respectively. The Pdx1-IR$E S$ - $m$ Cherry sequence was subcloned to replace the existing eGFP sequence of the HMD vector to generate HMD-Pdx1. Supplementary Figure 2: in vitro NOD-derived MSC adipogenesis, osteogenesis, and chondrogenesis (a) NOD-derived MSCs at early, mid, and late passage numbers were cultured in vitro with control or adipogenic differentiation media. Lipid development in mature (white arrow) and immature adipocytes (yellow arrow) was assessed following Oil Red O staining. (b) NOD-derived MSCs at early, mid, and late passage numbers were cultured in vitro with control or osteogenic differentiation media. Calcium development (white arrows) was assessed with Alizarin Red staining. (c) NOD-derived MSCs at early, mid, and late passage numbers were cultured in vitro with control or chondrogenic differentiation media for 18 days. Filamentous glycosaminoglycan development during chondrogenesis (indicated by white arrows) was assessed with Alcian blue staining. Images were acquired on a Leica DM microscope, 20x magnification, scale bar $=100 \mu \mathrm{m}$. Supplementary Table 1: list of oligonucleotide primers for RT-PCR. Supplementary Table 2A: average 
stained cell acquisition and analysis of NOD BMSCs and double-positive cells. Supplementary Table 2B: average purity analysis of sorted BMSCs and double-positive cells. Supplementary Table 3A: persistence of bioluminescent signal in NOD/Scid mice. Supplementary Table 3B: persistence of bioluminescent signal in NOD mice. Supplementary Table 4A: cell acquisition analysis of lentivirus-transduced BMSCs. Supplementary Table 4B: sorted cell purity analysis of lentivirus-transduced BMSCs. Supplementary Table 5A: significance in blood glucose concentration following BMSC-INS-FUR transplant compared to normal controls. Supplementary Table 5B: significance in body weight following BMSC-INS-FUR transplant compared to normal controls. (Supplementary Materials)

\section{References}

[1] M. A. Atkinson and N. K. Maclaren, "The pathogenesis of insulin-dependent diabetes mellitus," The New England Journal of Medicine, vol. 331, no. 21, pp. 1428-1436, 1994.

[2] R. M. Meloche, "Transplantation for the treatment of type 1 diabetes," World Journal of Gastroenterology, vol. 13, no. 47, pp. 6347-6355, 2007.

[3] B. Ren, B. A. O’Brien, M. A. Swan et al., "Long-term correction of diabetes in rats after lentiviral hepatic insulin gene therapy," Diabetologia, vol. 50, no. 9, pp. 1910-1920, 2007.

[4] B. Ren, B. A. O'Brien, M. R. Byrne et al., "Long-term reversal of diabetes in non-obese diabetic mice by liver-directed gene therapy," The Journal of Gene Medicine, vol. 15, no. 1, pp. 28-41, 2013.

[5] D. Gerace, B. Ren, W. J. Hawthorne et al., "Pancreatic transdifferentiation in porcine liver following lentiviral delivery of human furin-cleavable insulin," Transplantation Proceedings, vol. 45, no. 5, pp. 1869-1874, 2013.

[6] Q.-P. Xie, H. Huang, B. Xu et al., "Human bone marrow mesenchymal stem cells differentiate into insulin-producing cells upon microenvironmental manipulation in vitro," Differentiation, vol. 77, no. 5, pp. 483-491, 2009.

[7] F. W. Pagliuca, J. R. Millman, M. Gürtler et al., "Generation of functional human pancreatic $\beta$ cells in vitro," Cell, vol. 159, no. 2, pp. 428-439, 2014.

[8] S.-H. Oh, T. M. Muzzonigro, S. H. Bae, J. M. LaPlante, H. M. Hatch, and B. E. Petersen, "Adult bone marrow-derived cells trans-differentiating into insulin-producing cells for the treatment of type I diabetes," Laboratory Investigation, vol. 84, no. 5, pp. 607-617, 2004.

[9] D. Q. Tang, L. Z. Cao, B. R. Burkhardt et al., "In vivo and in vitro characterization of insulin-producing cells obtained from murine bone marrow," Diabetes, vol. 53, no. 7, pp. 1721-1732, 2004.

[10] X. H. Wu, C. P. Liu, K. F. Xu et al., "Reversal of hyperglycemia in diabetic rats by portal vein transplantation of islet-like cells generated from bone marrow mesenchymal stem cells," World Journal of Gastroenterology, vol. 13, no. 24, pp. 3342-3349, 2007.

[11] S. K. Chakrabarti and R. G. Mirmira, "Transcription factors direct the development and function of pancreatic $\beta$ cells," Trends in Endocrinology \& Metabolism, vol. 14, no. 2, pp. 78-84, 2003.

[12] D. Gerace, R. Martiniello-Wilks, B. A. O'Brien, and A. M. Simpson, "The use of $\beta$-cell transcription factors in engineering artificial $\beta$-cells from non-pancreatic tissue," Gene Therapy, vol. 22, no. 1, pp. 1-8, 2015.

[13] H. Kojima, M. Fujimiya, K. Matsumura et al., "NeuroD-betacellulin gene therapy induces islet neogenesis in the liver and reverses diabetes in mice," Nature Medicine, vol. 9, no. 5, pp. 596-603, 2003.

[14] O. Karnieli, Y. Izhar-Prato, S. Bulvik, and S. Efrat, "Generation of insulin-producing cells from human bone marrow mesenchymal stem cells by genetic manipulation," Stem Cells, vol. 25, no. 11, pp. 2837-2844, 2007.

[15] Y. Li, R. Zhang, H. Qiao et al., "Generation of insulin-producing cells from PDX-1 gene-modified human mesenchymal stem cells," Journal of Cellular Physiology, vol. 211, no. 1, pp. 36-44, 2007.

[16] G. Lin, G. Wang, G. Liu et al., "Treatment of type 1 diabetes with adipose tissue-derived stem cells expressing pancreatic duodenal homeobox 1," Stem Cells and Development, vol. 18, no. 10, pp. 1399-1406, 2009.

[17] H. Kajiyama, T. S. Hamazaki, M. Tokuhara et al., " $P d x 1$-transfected adipose tissue-derived stem cells differentiate into insulin-producing cells in vivo and reduce hyperglycemia in diabetic mice," The International Journal of Developmental Biology, vol. 54, no. 4, pp. 699-705, 2010.

[18] B. Ren, C. Tao, M. A. Swan et al., "Pancreatic transdifferentiation and glucose-regulated production of human insulin in the H4IIE rat liver cell line," International Journal of Molecular Sciences, vol. 17, no. 4, p. 534, 2016.

[19] B. P. Dodson and A. D. Levine, "Challenges in the translation and commercialization of cell therapies," BMC Biotechnology, vol. 15 , no. 1, p. 70, 2015.

[20] M. Dominici, K. Le Blanc, I. Mueller et al., "Minimal criteria for defining multipotent mesenchymal stromal cells. The International Society for Cellular Therapy position statement," Cytotherapy, vol. 8, no. 4, pp. 315-317, 2006.

[21] J. Galipeau, M. Krampera, J. Barrett et al., "International Society for Cellular Therapy perspective on immune functional assays for mesenchymal stromal cells as potency release criterion for advanced phase clinical trials," Cytotherapy, vol. 18, no. 2, pp. 151-159, 2016.

[22] S. Ferber, A. Halkin, H. Cohen et al., "Pancreatic and duodenal homeobox gene 1 induces expression of insulin genes in liver and ameliorates streptozotocin-induced hyperglycemia," Nature Medicine, vol. 6, no. 5, pp. 568-572, 2000.

[23] National Health and Medical Research Council, Australian Code for the Care and Use of Animals for Scientific Purposes, NHMRC, 2013.

[24] H. S. Wang, S. C. Hung, S. T. Peng et al., "Mesenchymal stem cells in the Wharton's jelly of the human umbilical cord," Stem Cells, vol. 22, no. 7, pp. 1330-1337, 2004.

[25] J. Lawandi, C. Tao, B. Ren et al., "Reversal of diabetes following transplantation of an insulin-secreting human liver cell line: Melligen cells," Molecular Therapy - Methods \& Clinical Development, vol. 2, article 15011, 2015.

[26] M. M. Bonab, K. Alimoghaddam, F. Talebian, S. H. Ghaffari, A. Ghavamzadeh, and B. Nikbin, "Aging of mesenchymal stem cell in vitro," BMC Cell Biology, vol. 7, no. 1, p. 14, 2006.

[27] M. J. Peffers, J. Collins, Y. Fang et al., “Age-related changes in mesenchymal stem cells identified using a multi-omics approach," European Cells \& Materials, vol. 31, pp. 136-159, 2016. 
[28] A. Stolzing, E. Jones, D. McGonagle, and A. Scutt, “Age-related changes in human bone marrow-derived mesenchymal stem cells: consequences for cell therapies," Mechanisms of Ageing and Development, vol. 129, no. 3, pp. 163-173, 2008.

[29] D. Nawrocka, K. Kornicka, J. Szydlarska, and K. Marycz, "Basic fibroblast growth factor inhibits apoptosis and promotes proliferation of adipose-derived mesenchymal stromal cells isolated from patients with type 2 diabetes by reducing cellular oxidative stress," Oxidative Medicine and Cellular Longevity, vol. 2017, Article ID 3027109, 22 pages, 2017.

[30] J. M. Yu, X. Wu, J. M. Gimble, X. Guan, M. A. Freitas, and B. A. Bunnell, "Age-related changes in mesenchymal stem cells derived from rhesus macaque bone marrow," Aging Cell, vol. 10, no. 1, pp. 66-79, 2011.

[31] M. Marędziak, K. Marycz, K. A. Tomaszewski, K. Kornicka, and B. M. Henry, "The influence of aging on the regenerative potential of human adipose derived mesenchymal stem cells," Stem Cells International, vol. 2016, Article ID 2152435, 15 pages, 2016.

[32] J. D. Kretlow, Y.-Q. Jin, W. Liu et al., "Donor age and cell passage affects differentiation potential of murine bone marrow-derived stem cells," BMC Cell Biology, vol. 9, no. 1, p. 60, 2008.

[33] K. Kornicka, K. Marycz, K. A. Tomaszewski, M. Maredziak, and A. Smieszek, "The effect of age on osteogenic and adipogenic differentiation potential of human adipose derived stromal stem cells (hASCs) and the impact of stress factors in the course of the differentiation process," Oxidative Medicine and Cellular Longevity, vol. 2015, Article ID 309169, 20 pages, 2015.

[34] D. Zhang, H. Lu, Z. Chen et al., "High glucose induces the aging of mesenchymal stem cells via Akt/mTOR signaling," Molecular Medicine Reports, vol. 16, no. 2, pp. 1685-1690, 2017.

[35] Z. M. Bai, X. D. Deng, J. D. Li et al., "Arterially transplanted mesenchymal stem cells in a mouse reversible unilateral ureteral obstruction model: in vivo bioluminescence imaging and effects on renal fibrosis," Chinese Medical Journal, vol. 126, no. 10, pp. 1890-1894, 2013.

[36] J. A. Ankrum, J. F. Ong, and J. M. Karp, "Mesenchymal stem cells: immune evasive, not immune privileged," Nature Biotechnology, vol. 32, no. 3, pp. 252-260, 2014.

[37] K. M. Podetz-Pedersen, V. Vezys, N. V. Somia, S. J. Russell, and R. S. McIvor, "Cellular immune response against firefly luciferase after sleeping beauty-mediated gene transfer in vivo," Human Gene Therapy, vol. 25, no. 11, pp. 955-965, 2014.

[38] Y. Yin, Y. Takahashi, A. Hamana, M. Nishikawa, and Y. Takakura, "Effects of transgene expression level per cell in mice livers on induction of transgene-specific immune responses after hydrodynamic gene transfer," Gene Therapy, vol. 23, no. 7, pp. 565-571, 2016.

[39] I. Rosova, M. Dao, B. Capoccia, D. Link, and J. A. Nolta, "Hypoxic preconditioning results in increased motility and improved therapeutic potential of human mesenchymal stem cells," Stem Cells, vol. 26, no. 8, pp. 2173-2182, 2008.

[40] T. E. Meyerrose, D. A. De Ugarte, A. A. Hofling et al., "In vivo distribution of human adipose-derived mesenchymal stem cells in novel xenotransplantation models," Stem Cells, vol. 25, no. 1, pp. 220-227, 2007.

[41] T. E. Meyerrose, M. Roberts, K. K. Ohlemiller et al., "Lentiviral-transduced human mesenchymal stem cells persistently express therapeutic levels of enzyme in a xenotransplantation model of human disease," Stem Cells, vol. 26, no. 7, pp. 1713-1722, 2008.

[42] E. W. Choi, I. S. Shin, S. Y. Park et al., "Characteristics of mouse adipose tissue-derived stem cells and therapeutic comparisons between syngeneic and allogeneic adipose tissue-derived stem cell transplantation in experimental autoimmune thyroiditis," Cell Transplantation, vol. 23, no. 7, pp. 873-887, 2014.

[43] J. Liang, X. Li, H. Zhang et al., "Allogeneic mesenchymal stem cells transplantation in patients with refractory RA," Clinical Rheumatology, vol. 31, no. 1, pp. 157-161, 2012.

[44] G. Qing-Song, Z. Ming-Yan, W. Lei et al., "Combined transfection of the three transcriptional factors, PDX-1, NeuroD1, and MafA, causes differentiation of bone marrow mesenchymal stem cells into insulin-producing cells," Experimental Diabetes Research, vol. 2012, Article ID 672013, 10 pages, 2012.

[45] K. A. D'Amour, A. G. Bang, S. Eliazer et al., "Production of pancreatic hormone-expressing endocrine cells from human embryonic stem cells," Nature Biotechnology, vol. 24, no. 11, pp. 1392-1401, 2006.

[46] D. Gerace, R. Martiniello-Wilks, N. T. Nassif, S. Lal, R. Steptoe, and A. M. Simpson, "CRISPR-targeted genome editing of mesenchymal stem cell-derived therapies for type 1 diabetes: a path to clinical success?," Stem Cell Research \& Therapy, vol. 8, no. 1, p. 62, 2017.

[47] J. E. Frith, B. Thomson, and P. G. Genever, "Dynamic three-dimensional culture methods enhance mesenchymal stem cell properties and increase therapeutic potential," Tissue Engineering Part C: Methods, vol. 16, no. 4, pp. 735-749, 2010.

[48] C. Karlsson, K. Emanuelsson, F. Wessberg et al., "Human embryonic stem cell-derived mesenchymal progenitors-potential in regenerative medicine," Stem Cell Research, vol. 3, no. 1, pp. 39-50, 2009. 


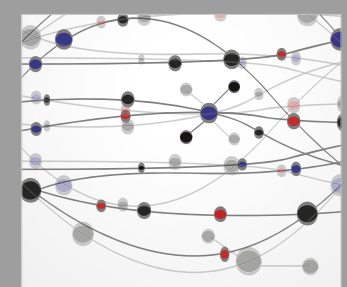

The Scientific World Journal
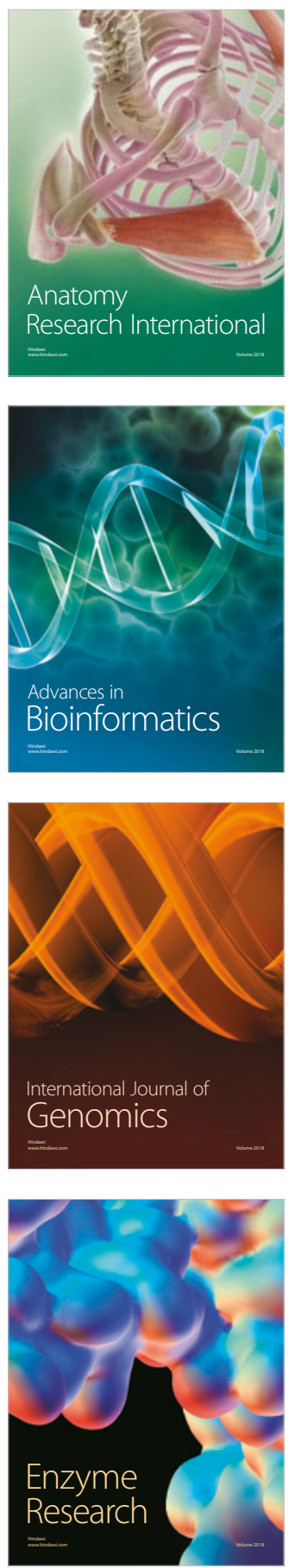
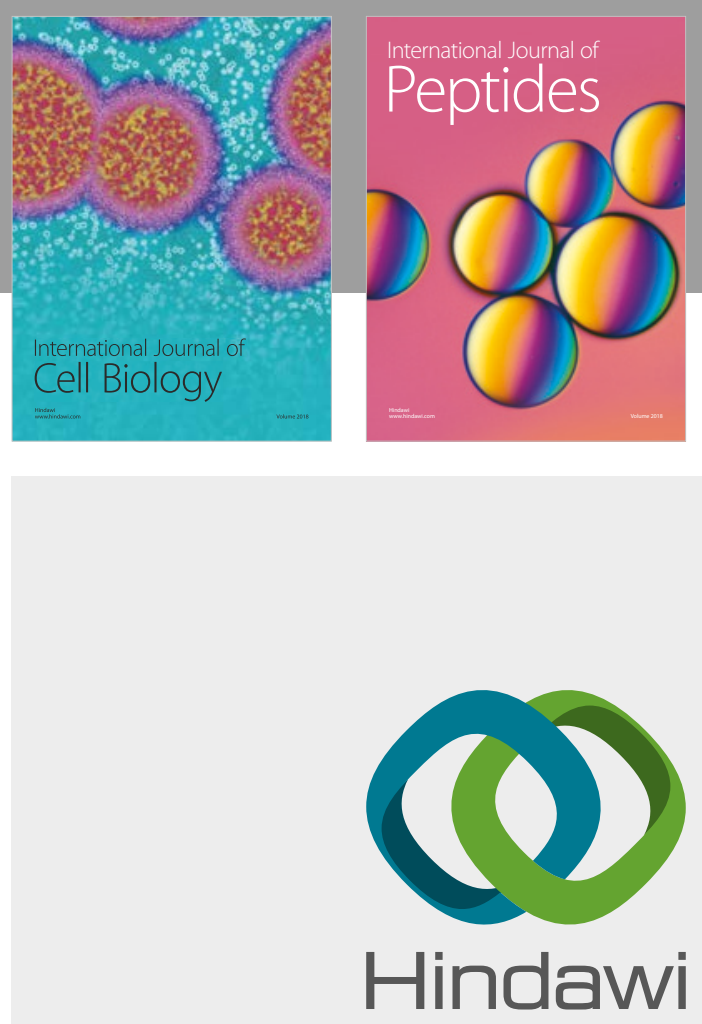

Submit your manuscripts at

www.hindawi.com
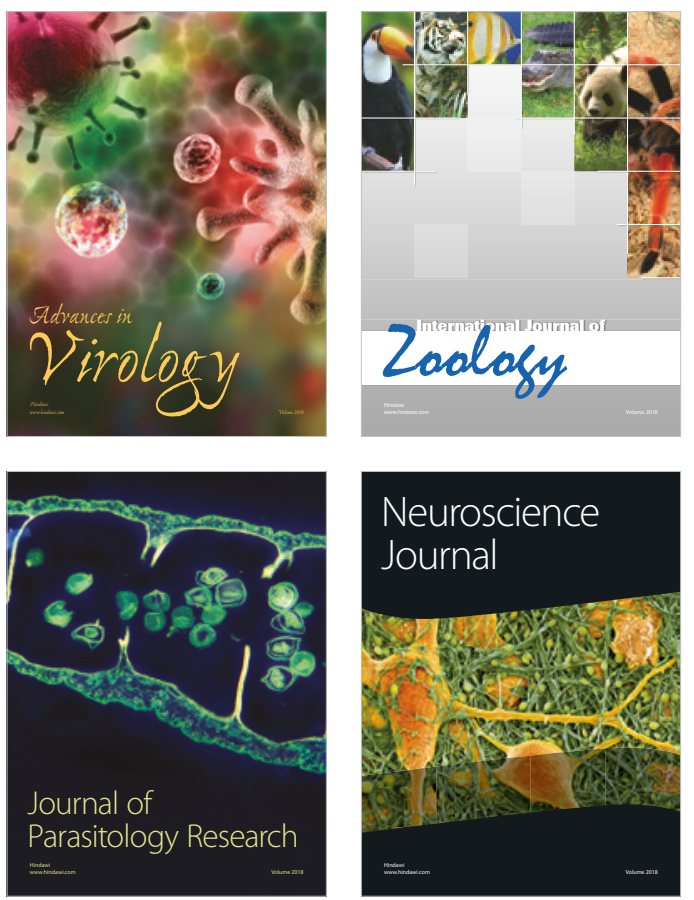
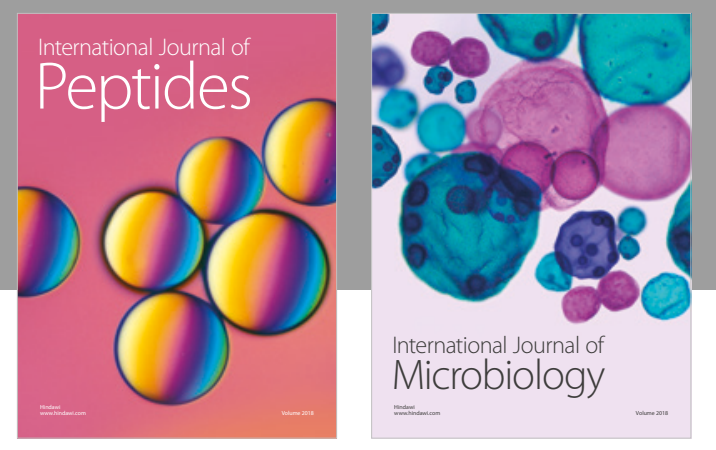

nternational Journal of Microbiology
Journal of
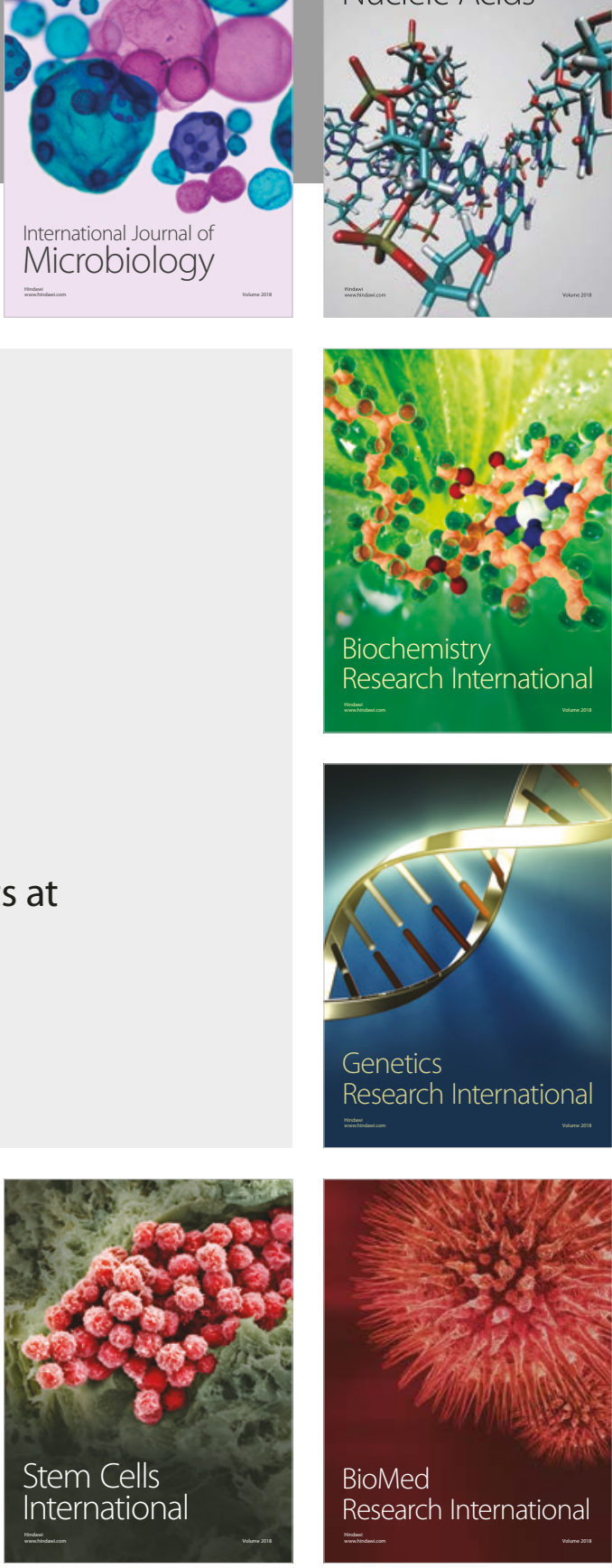
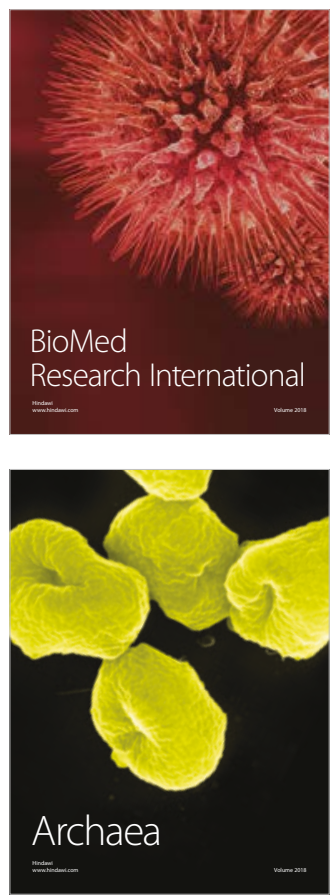